\title{
The Environmental Effects of Crop Price Increases: Nitrogen Losses in the U.S. Corn Belt
}

\author{
Nathan P. Hendricks ${ }^{a *}$, Sumathy Sinnathamby ${ }^{b}$, Kyle Douglas-Mankin $^{b}$, \\ Aaron $\mathrm{Smith}^{c}$, Daniel A. Sumner ${ }^{c}$, and Dietrich H. Earnhart ${ }^{d}$
}

August 2014

\begin{abstract}
High corn prices cause farmers to plant more corn on fields that were planted to corn in the previous year, rather than alternating between corn and soybeans. Cultivating corn after corn requires greater nitrogen fertilizer and some of this nitrogen flows into waterways and causes environmental damage. We estimate the effect of crop prices on nitrogen losses for most fields in Iowa, Illinois, and Indiana using crop data from satellite imagery. Spatial variation in these high-resolution estimates highlights the fact that the environmental effects of agriculture depend not only on what is grown, but also on where and in what sequence it is grown. Our results suggest that the change in corn and soybean prices due to a billion gallons of ethanol production expands the size of the hypoxic zone in the Gulf of Mexico by roughly 30 square miles on average, although there is considerable uncertainty in this estimate.
\end{abstract}

Keywords: Crop Rotation, Spatial, Water Quality, Dynamic Panel JEL codes: Q15, Q53

${ }^{a}$ Department of Agricultural Economics, Kansas State University, Manhattan, KS 66506, United States

${ }^{b}$ Department of Biological and Agricultural Engineering, Kansas State University, Manhattan, KS 66506, United States

${ }^{c}$ Department of Agricultural and Resource Economics, University of California Davis, Davis, CA 95616, United States

${ }^{d}$ Department of Economics, University of Kansas, Lawrence, KS 66045, United States

* Corresponding author: Fax: +1 785532 6925. E-mail address: nph@ksu.edu.

\section{Acknowledgments}

The authors thank Michael Roberts, JunJie Wu, three anonymous reviewers, and seminar participants at the University of Nebraska for helpful comments. This material is based upon work supported by the United States Department of Agriculture under Agreement No. 58-0111-10-005 and by the National Science Foundation under Award No. EPS-0903806 and matching support from the State of Kansas through the Kansas Board of Regents.

(C) 2018. This manuscript version is made available under the CC-BY-NC-ND 4.0 license http://creativecommons.org/licenses/by-nc-nd/4.0/ 


\section{Introduction}

Agricultural production generates externalities through its effects on environmental goods such as water quality, wildlife habitat, and carbon sequestration. As crop prices change, farmers change their planted acreage, which in turn changes the generation of these externalities. For example, it has been argued that higher crop prices due to the production of ethanol have increased nutrient losses from the Corn Belt into surface water (e.g., Donner and Kucharik, 2008; Secchi et al., 2011; Langpap and Wu, 2011), increased monoculture production systems that are associated with losses of biocontrol services (Landis et al., 2008), and increased greenhouse gases due to agricultural land use expansion (e.g., Searchinger et al., 2008).

In this article, we estimate the marginal response of nitrogen losses to changes in crops prices for almost all cultivated fields in Iowa, Illinois, and Indiana. Nutrient losses from crop production in this region are cited as a leading cause of the "dead zone" in the Gulf of Mexico (Dale et al., 2010). The Economist (2012) calls the dead zone an "ecological disaster" that results in losses to fisheries valued at roughly $\$ 2.8$ billion per year, among other damages. Rabotyagov et al. (2014) provide an overview of the impact of hypoxic conditions on ecosystem services and note that dead zones are an increasing concern in many regions of the world. Local water quality is also a serious concern within this region due to nutrient losses. For example, the Illinois EPA (2012) lists several impaired waters and cites crop production as one of the leading sources of these impairments. Several studies have shown that high nutrient concentrations in local water bodies are directly related to row crop production (Schilling and Libra, 2000; Arbuckle and Downing, 2001).

Marginal nitrogen losses from changes in crop prices depend on land use response to prices

and the effect of land use changes on nitrogen losses. We estimate the land use response to prices using the econometric model from Hendricks, Smith, and Sumner (2014). We then 
integrate these estimates with the Soil and Water Assessment Tool (SWAT) to simulate the ensuing effects on nitrogen losses. ${ }^{1}$

For the main explanatory variables in our econometric model, we use futures prices measured during a pre-harvest period on contracts for post-harvest delivery. We adjust for spatial variation and government payments, so our price variables proxy for the farmer's output price expectations at planting time. We assume that these expected price variables are exogenous to planted crop acreage. The dominant sources of variation in these prices are the recent increase due to strong global demand and U.S. ethanol production (Carter, Rausser, and Smith, 2013) and prior-year yield shocks (Roberts and Schlenker, 2013). These two sources of variation both represent shocks to the demand for current-year supply, so they can be used to identify the acreage response. Nonetheless, our exogeneity assumption would fail if planted acreage were affected by anticipated yield shocks and if futures prices were to respond to the anticipated change in planted acreage. Supporting exogeneity, Hendricks, Janzen, and Smith (2014) find only a small bias in regressions with acreage as the dependent variable rather than production. We assess the robustness of our results to our exogeneity assumption by including the realized yield shock as a control to proxy for anticipated yield shocks.

We estimate the marginal nitrogen losses at a high spatial resolution. Our estimates account for spatial variation in crop rotations, land-use response, and water-quality impacts, so they reveal how the environmental effects of agriculture depend not only on what is grown, but especially on where and in what rotation it is grown. We also report the aggregate marginal losses as nitrogen loss elasticities with respect to changes in crop prices. These elasticity estimates are important for understanding the effect of government policies on nitrogen losses from the Corn Belt. For example, we use these elasticities to estimate the effect of ethanol production in the United States on the size of the hypoxic zone in the Gulf of

\footnotetext{
${ }^{1}$ The SWAT model has been widely used to assess the impacts of landcover and management practices on water and nutrients at the field and watershed scale (Gassman et al., 2007; Douglas-Mankin, Srinivasan, and Arnold, 2010; Tuppad et al., 2011).
} 
Mexico. Our elasticity estimates are also important inputs for estimating the effect of U.S. farm subsidy programs on nitrogen losses. Our research is related to Muller and Mendelsohn (2007) who estimate the aggregate marginal damages and the spatial heterogeneity of marginal damages from air pollution.

Accurately estimating the environmental damages associated with crop price changes requires a model that incorporates production dynamics. Crop rotations - alternating crops between years for a given field - are common because planting a crop on the same field in consecutive years decreases crop productivity, increases pest populations, and raises costs. It is common for farmers in the Corn Belt to rotate between corn and soybeans. Planting corn after soybeans increases corn yields (holding inputs constant) and reduces the optimal fertilizer application because nitrogen carries over from soybeans the previous year. ${ }^{2}$ The dynamics of crop rotations have important water quality implications because corn planted after corn leads to greater nitrogen losses than corn planted after soybeans-likely due to the fact that more fertilizer is applied to corn after corn.

We account for the dynamics in our econometric model by specifying the year-to-year transitions between growing corn and soybeans as a first order Markov process. We use the resulting Markov transition probabilities to calculate the probability of a corn-aftercorn sequence, a corn-soybean rotation, and a soybeans-after-soybeans sequence - as well as the short-run (1 year) and long-run (5-10 years) marginal effects of price changes on these sequences. We find that, in response to a price shock, changes in nitrogen losses are smaller in the short run than in the long run. This result arises because nitrogen losses are largest from fields with consecutive years of corn, and corn-after-corn acreage responds to a price shock less in the short run than in the long run. For example, if the price of corn increases permanently, some land switches from a corn-soybean rotation to continuous corn. Roughly half of this land was planted to corn in the previous year, so it experiences relatively high nitrogen losses beginning in the first year. However, the other half of this land was planted

\footnotetext{
${ }^{2}$ Soybeans are a nitrogen-fixing crop.
} 
to soybeans in the previous year, which mitigates the nitrogen losses from planting corn in the first year. These dynamics stand in contrast to the dynamics of aggregate corn acreage. Using the same model, Hendricks, Smith, and Sumner (2014) show that aggregate corn acreage responds to price shocks more in the short run than in the long run. We explain in the first section how these seemingly contradictory results are consistent with each other.

Accurately estimating the environmental damages associated with crop price changes also requires a model that incorporates spatial heterogeneity. There are two reasons to model spatial heterogeneity in our context: (i) the spatial distribution of the nitrogen losses is inherently important, and (ii) estimates of aggregate nitrogen losses may be biased if they ignore spatial heterogeneity. Spatially explicit estimates of marginal nitrogen losses are useful for assessing the effects of crop price changes on regional water quality. Furthermore, heterogeneous incentives to rotate crops and heterogeneous responses to prices can induce bias in dynamic panel econometric models (Robertson and Symons, 1992; Pesaran and Smith, $1995)$ and thus bias our estimates of aggregate nitrogen losses. ${ }^{3}$

We account for spatially heterogeneous incentives to rotate crops and heterogeneous responses to prices by estimating the econometric model separately for 108 soil-climatic regimes. We define these regimes using soil taxonomy classifications within Major Land Resource Areas as identified by the Natural Resources Conservation Service. We find that ignoring spatial heterogeneity causes estimated marginal nitrogen losses to be $25-50 \%$ smaller. Accounting for spatial heterogeneity in our integrated model also allows us to estimate where marginal nitrogen losses are likely to be largest from crop price changes.

Several previous articles that link land use change to environmental outcomes do not allow spatially heterogeneous response to price in the econometric model (Wu et al., 2004; Langpap, Hascic, and Wu, 2008; Lacroix and Thomas, 2011; Fezzi and Bateman, 2011). In these models, the predicted land use varies spatially due to the inclusion of explanatory

\footnotetext{
${ }^{3}$ Ignoring heterogeneous responses of land use to prices could also lead to biased estimates of nitrogen losses if the size of the price response is correlated with the change in nitrogen losses from changing land uses, but this correlation is small in our application.
} 
variables derived from disaggregated soils and climatic data but the parameters of these models do not vary across space. The most common approach of other studies is to allow spatial heterogeneity of land use change through the use of spatial regimes, i.e., dividing space into multiple sub-regions and estimating different parameters for each sub-region. ${ }^{4}$ Langpap and $\mathrm{Wu}$ (2011) estimate separate land use models for two groups of U.S. states. Newburn and Berck (2006) allow coefficients to differ by four regions and model the remaining heterogeneity within regions using a random parameters logit model. Several articles use land capability classifications (LCC) as spatial regimes (Lichtenberg, 1989; Plantinga, 1996; Lubowski, Plantinga, and Stavins, 2008; Nelson et al., 2008). In Iowa, Illinois, and Indiana, 94 percent of the cropland is in three LCC's, so this classification would allow little spatial heterogeneity if applied to our sample.

We estimate the econometric model of crop rotation response to price using crop data derived from satellite imagery - the Cropland Data Layer from USDA - that provides a comprehensive accounting of crops in Iowa, Illinois, and Indiana from 2000 to 2010. Field boundaries are approximated with Common Land Unit boundaries as defined by the Farm Service Agency. Our field-level dataset for the econometric analysis contains roughly 8.75 million observations. We also investigate the possible conversions of land to crop production from the Conservation Reserve Program in response to higher crop prices using county-level data. We use the Soil and Water Assessment Tool (SWAT) to estimate how changes in land use affect nitrogen losses from each field. We then merge spatially-explicit SWAT results for nitrogen losses at the edge-of-the-field with spatially-explicit results from the econometric model.

An alternative empirical strategy is to directly estimate the effect of crop prices on observed water quality outcomes rather than using a biophysical model. However, the timing of nitrate-nitrogen concentration in surface water varies substantially across space and crop years due to weather (Jayasinghe, Miller, and Hatfield, 2012) and other biophysical factors

\footnotetext{
${ }^{4}$ Another approach for allowing coefficients to vary spatially is through locally weighted regression (e.g., Cho, Bowker, and Park, 2006).
} 
(Green et al., 2014). Thus, it would be difficult to obtain meaningful estimates of the effect of crop prices on observed nitrate-nitrogen concentrations, especially if one were to model the dynamics and spatial heterogeneity. For these reasons, we focus on estimating the economic response of farmers to crop prices, and we take as given the biophysical processes as characterized in the best available model to quantify edge-of-field nitrogen losses.

\section{Model of Crop Rotation Response to Price}

We separately estimate price responses along the "rotational margin" (transitions between corn and soybeans) and the "other crop margin" (transitions between corn or soybeans and other crops). ${ }^{5}$ This model setup implies that farmers make sequential decisions, first deciding whether or not to plant one of the two main crops (corn and soybeans) or another crop and then deciding which crop to plant. We find very small price responses at the other crop margin, so modeling the two margins independently is likely to trivially affect our results.

\subsection{Econometric Model}

We use the same econometric model as Hendricks, Smith, and Sumner (2014). ${ }^{6}$ They formulate a conceptual model similar to that of Hennessy (2006) for a farmer's dynamic optimization of crop rotations. Assuming that prices beyond the current year are expected to remain constant and assuming one-year memory of the crop rotation - that is, only the crop from the previous year affects returns in the current year-Hendricks, Smith, and Sumner (2014) show that the optimal planting decision is conditional on the previous crop. From this conceptual model, they derive an econometric model of first-order Markov transition

\footnotetext{
${ }^{5}$ Hendricks, Smith, and Sumner (2014) refer to the "other crop margin" as the "extensive margin." In both cases it refers to transitions between corn or soybeans and other crops. We exclude grassland completely.

${ }^{6}$ There are two differences between the estimation in this paper and Hendricks, Smith, and Sumner (2014). First, we estimate the model separately for 108 soil-climatic regimes in this paper whereas Hendricks, Smith, and Sumner (2014) only use 24 regimes. Second, in this paper we calculate the rotational marginal effects as the marginal effect at the rotational margin times the probability of planting corn or soybeans from the other crop margin model. Hendricks, Smith, and Sumner (2014) calculate the average rotational marginal effects as the marginal effect at the rotational margin averaged across observations in the rotational margin dataset. We alter the method slightly in this paper since our focus is the spatial heterogeneity of the marginal effects. The difference in method has a negligible effect on estimates of aggregate elasticities.
} 
probabilities. We write the set of linear reduced-form Markov transition probabilities as follows:

$$
\begin{aligned}
& \Phi_{i t}^{c c}=\operatorname{Prob}\left(c_{i t}=1 \mid c_{i, t-1}=1\right)=\lambda_{1 i}+\beta_{1 i}^{c} p_{i t}^{c}+\beta_{1 i}^{s} p_{i t}^{s}+\boldsymbol{\theta}_{1 i}^{\prime} \mathbf{x}_{i}+\kappa_{1 i} t, \\
& \Phi_{i t}^{s c}=\operatorname{Prob}\left(c_{i t}=1 \mid c_{i, t-1}=0\right)=\lambda_{2 i}+\beta_{2 i}^{c} p_{i t}^{c}+\beta_{2 i}^{s} p_{i t}^{s}+\boldsymbol{\theta}_{2 i}^{\prime} \mathbf{x}_{i}+\kappa_{2 i} t
\end{aligned}
$$

where $\Phi_{i t}^{c c}$ denotes the probability of a transition from corn to corn on field $i$ in year $t, \Phi_{i t}^{s c}$ denotes the probability of a transition from soybeans to corn, $p_{i t}^{c}$ is the expected effective price of corn including government payments, $p_{i t}^{s}$ is the expected effective price of soybeans including government payments, $\mathbf{x}_{i}$ is a vector of field characteristics (an indicator of large spring rainfall, share clay, share silt, slope, and share of county irrigated), and $t$ is a time trend. ${ }^{7}$ An indicator of large spring rainfall is included as a regressor because heavy spring rains may delay corn planting and cause some farmers to switch to soybeans. A time trend is included in the transition probabilities to account for the possibility that the yield advantage of rotating corn and soybeans has diminished over time as suggested by Duffy (2011). Note that the probability of planting soybeans given that the previous crop was corn is $\Phi_{i t}^{c s}=$ $1-\Phi_{i t}^{c c}$, and that the probability of planting soybeans given that the previous crop was soybeans is $\Phi_{i t}^{s s}=1-\Phi_{i t}^{s c}$. We write coefficients with an $i$ subscript to denote heterogeneity across fields.

The probability of planting corn in year $t$, denoted $\Pi_{i t}^{c}$, is the probability of planting corn given that corn was previously planted multiplied by the probability of planting corn in the previous year plus the probability of planting corn given that soybeans were previously planted multiplied by the probability of planting soybeans in the previous year:

$$
\Pi_{i t}^{c}=\Phi_{i t}^{c c} \Pi_{i t-1}^{c}+\Phi_{i t}^{s c}\left(1-\Pi_{i t-1}^{c}\right)
$$

\footnotetext{
${ }^{7}$ We omit input prices (e.g., the price of fertilizer) because of the challenge of identifying the effect of these input prices separately from crop prices with only 11 years of data. However, using crop budgets, Hendricks, Smith, and Sumner (2014) show that changes in crop prices have much larger effects on crop rotation returns than similar proportional changes in fertilizer prices, so we expect the bias from this omission to be small.
} 
In the long run (i.e., steady-state) $\left.\Pi_{i t}^{c}\right|_{L R}=\Pi_{i t}^{c}=\Pi_{i, t-1}^{c}$. Rearranging (3) gives the long-run probability in terms of estimated transition probabilities: ${ }^{8}$

$$
\left.\Pi_{i t}^{c}\right|_{L R}=\frac{\Phi_{i t}^{s c}}{\Phi_{i t}^{s c}+\left(1-\Phi_{i t}^{c c}\right)} .
$$

The short-run change in the probability of planting corn with respect to a change in price equals the derivative of the transition probability functions in (3) evaluated at the long-run probabilities:

$$
\left.\frac{\partial \Pi_{i t}^{c}}{\partial p_{i t}^{j}}\right|_{S R}=\left.\beta_{1 i}^{j} \Pi_{i t}^{c}\right|_{L R}+\beta_{2 i}^{j}\left(1-\left.\Pi_{i t}^{c}\right|_{L R}\right)
$$

where $p_{i t}^{j}$ is the expected price of crop $j$. In other words, the short-run marginal effect of price is the weighted average of the marginal effects of the transition probabilities, where the weights correspond to the long-run probability of planting corn and the long-run probability of planting soybeans. The long-run marginal effect of price is obtained by taking the derivative of (4):

$$
\left.\frac{\partial \Pi_{i t}^{c}}{\partial p_{i t}^{j}}\right|_{L R}=\frac{\beta_{2 i}^{j}\left(1-\Phi_{i t}^{c c}\right)+\beta_{1 i}^{j} \Phi_{i t}^{s c}}{\left[\Phi_{i t}^{s c}+\left(1-\Phi_{i t}^{c c}\right)\right]^{2}}
$$

The probability of planting corn two years in a row, denoted $\Pi_{i t}^{c c}$, is the probability of planting corn given that corn was previously planted multiplied by the probability of planting corn in the previous year:

$$
\Pi_{i t}^{c c}=\Phi_{i t}^{c c} \Pi_{i t-1}^{c}
$$

The long-run probability of planting corn two years in a row is obtained by substituting (4) into (7). Similarly, we can write the probability of planting a corn-soybean rotation $\left(\Pi_{i t}^{c-s}\right)$ and soybeans after soybeans $\prod_{i t}^{s s}$ as follows:

$$
\begin{aligned}
\Pi_{i t}^{c-s} & =\frac{1}{2}\left[\Phi_{i t}^{s c}\left(1-\Pi_{i t-1}^{c}\right)+\left(1-\Phi_{i t}^{c c}\right) \Pi_{i t-1}^{c}\right], \\
\Pi_{i t}^{s s} & =\left(1-\Phi_{i t}^{s c}\right)\left(1-\Pi_{i t-1}^{c}\right),
\end{aligned}
$$

\footnotetext{
${ }^{8}$ See Hamilton (1994, p. 683) for an alternative derivation.
} 
where the probability of a corn-soybean rotation is the average of the probability of corn after soybeans and the probability of soybeans after corn. Substituting equation (4) into equations (7)-(9) gives the long-run probability of observing a particular sequence of crops at a given price level, without conditioning on what was actually planted in a particular year.

The short-run marginal effect of price on the probability of planting corn after corn is the change in the probability of corn after corn, holding constant the probability of having previously planted corn:

$$
\left.\frac{\partial \Pi_{i t}^{c c}}{\partial p_{i t}^{j}}\right|_{S R}=\left.\beta_{1 i}^{j} \Pi_{i t}^{c}\right|_{L R} .
$$

the long-run marginal effect of price accounts for changes in the probability that corn was previously planted as follows:

$$
\left.\frac{\partial \Pi_{i t}^{c c}}{\partial p_{i t}^{j}}\right|_{L R}=\left.\beta_{1 i}^{j} \Pi_{i t}^{c}\right|_{L R}+\left.\Phi_{i t}^{c c} \frac{\partial \Pi_{i t}^{c}}{\partial p_{i t}^{j}}\right|_{L R} .
$$

The marginal effects of price on corn-soybeans and soybeans-after-soybeans sequences are defined similarly. Note, however, that theory does not give an expected sign for the effect of a change in the price of corn on the probability of a corn-soybean rotation. If an increase in the expected price of corn causes a larger reduction in soybeans after soybeans than an increase in corn after corn, then the probability of a corn-soybean rotation could increase on average due to an increase in the price of corn.

Hendricks, Smith, and Sumner (2014) show that aggregate corn acreage response to a price shock is larger in the short run than in the long run, whereas equations (10) and (11) indicate that the response of corn-after-corn acreage to a price shock is smaller in the short run than in the long run. To understand this relationship, consider a permanent increase in the price of corn. Some fields that previously planted continuous soybeans will switch to a corn-soybean rotation and some fields that previously planted a corn-soybean rotation will switch to continuous corn. Call the first set of fields Group A and the second set Group 
B. Group A fields all grow corn in the first year after the price shock, but in the long run only half of this land is planted to corn in a given year. Thus, the response of corn acreage among this group is greater in the short run than the long run. No Group A fields grow continuous corn, so the price shock causes no change in the probability of growing corn after corn. Group B fields grow corn in all years after the price shock, so the response of corn acreage among this group is the same in the short run and long run. Approximately half of Group B fields were planted to corn in the previous year, so in the first year after the price shock, they are growing corn after corn. The remaining Group B fields are growing corn after soybeans in the first year, but continuous corn thereafter. Thus, Group A drives the Hendricks, Smith, and Sumner (2014) result for corn acreage and Group B drives our result for rotations (see the online appendix for an illustration).

Our method of estimating the probability of different crop rotations differs from $\mathrm{Wu}$ et al. (2004). They predict the joint probability of planting corn in two consecutive years conditional on the crop that was planted in some initial year. ${ }^{9}$ Marginal effects in their model are conditional on the initial distribution of crops and cannot be interpreted as either short-run or long-run marginal effects. In contrast, our predicted probability of planting each rotation in equations (7)-(9) conditions on the long-run probability of planting corn for a particular price level.

For the other-crop margin, we also estimate linear first-order Markov transition probabilities:

$$
\begin{aligned}
& \operatorname{Prob}\left(c b_{i t}=1 \mid c b_{i, t-1}=1\right)=\lambda_{3 i}+\beta_{3 i}^{c b} p_{i t}^{c b}+\beta_{3 i}^{o} p_{i t}^{o}+\boldsymbol{\theta}_{3 i}^{\prime} \mathbf{x}_{i}+\kappa_{3 i} t \\
& \operatorname{Prob}\left(c b_{i t}=1 \mid c b_{i, t-1}=0\right)=\lambda_{4 i}+\beta_{4 i}^{c b} p_{i t}^{c b}+\beta_{4 i}^{o} p_{i t}^{o}+\boldsymbol{\theta}_{4 i}^{\prime} \mathbf{x}_{i}+\kappa_{4 i} t
\end{aligned}
$$

\footnotetext{
${ }^{9}$ Using our notation, Wu et al. (2004) estimate the probability of planting continuous corn as $\Phi_{i t}^{c c} \operatorname{Prob}\left(c_{i t-1}=1 \mid c_{i, t-2}\right)=\operatorname{Prob}\left(c_{i t}=1, c_{i t-1}=1 \mid c_{i, t-2}\right)$, where the equality follows from the Markov assumption.
} 
where $c b_{i t}$ equals one if corn or soybeans were planted and equals zero if another crop was planted, $p_{i t}^{c b}$ is an index of expected corn and soybean prices, and $p_{i t}^{o}$ is an index of expected wheat and alfalfa prices. We write the Markov transition probabilities in (1)-(2) and (12)(13) as depending only on expected prices in the current crop year, so we are assuming the expected price in the current year embodies the relevant price information for all future years. Relaxing this assumption would substantially increase the computational burden. We do not estimate transitions with land uses other than crops due to limitations of the Cropland Data Layer. In the results section, we discuss the potential magnitude of changes in Conservation Reserve Program acreage using county-level data and the implications for nitrogen losses. ${ }^{10}$ The long-run probability of planting corn or soybeans is denoted $\Pi_{i t}^{c b}$ and is defined similarly to equation (4).

The total probability of planting corn is the probability of planting corn given that corn or soybeans were planted multiplied by the probability of planting corn or soybeans:

$$
\operatorname{Prob}\left(c_{i t}=1\right)=\Pi_{i t}^{c} \Pi_{i t}^{c b}
$$

From this relationship, we derive the total marginal effect of price on field $i$ as follows:

$$
\frac{\partial \operatorname{Prob}\left(c_{i t}=1\right)}{\partial p_{i t}^{j}}=\underbrace{\frac{\partial \Pi_{i t}^{c}}{\partial p_{i t}^{j}} \Pi_{i t}^{c b}}_{\text {Rotational Margin }}+\underbrace{\Pi_{i t}^{c} \frac{\partial \Pi_{i t}^{c b}}{\partial p_{i t}^{j}}}_{\text {Other Crop Margin }}
$$

where we can define either short-run or long-run marginal effects. We calculate the aggregate price elasticity by averaging marginal effects of price across all fields - weighted by field sizeand converting into elasticity form.

\footnotetext{
${ }^{10}$ The impact of changes in Conservation Reserve Program acreage is likely larger in the Great Plains where CRP comprises a larger share of land use.
} 


\subsection{Estimation}

We model the coefficient heterogeneity across fields because spatial heterogeneity of the coefficients is inherently important and also because average estimates can be biased if coefficient heterogeneity is ignored (Hendricks, Smith, and Sumner, 2014). Our transition probabilities are heterogeneous dynamic panel models with a small time series $(T)$ dimension. OLS estimates that impose the same coefficients across all fields (i.e., pooling) are biased because the heterogeneous intercept is correlated with whether the field was previously planted to corn or soybeans. Pooled estimates are also biased due to heterogeneous coefficients on autocorrelated variables (Robertson and Symons, 1992; Pesaran and Smith, 1995). The error term in the pooled model is autocorrelated since it contains autocorrelated prices; thus, the error term is correlated with whether the field was previously planted to corn or soybeans. If we had a panel with large $T$, then we could estimate separate coefficients for each field. But with small $T$, field-specific estimates of a dynamic model suffer from small-sample bias.

Following Hendricks, Smith, and Sumner (2014), we manage the trade-off between heterogeneity bias and small-T bias by forming groups of similar fields and estimating separate coefficients for each group of fields. We refer to our estimator as a "conditional grouped coefficients" estimator. It is a grouped coefficients estimator because the coefficients differ across $108 \times 2$ groups of similar fields as defined by 108 soil-climatic regimes and 2 transition groups. We describe the construction of the soil-climatic regimes in section 3.3. It is a conditional estimator because, within each soil-climatic regime, we estimate the model separately for two sets of fields at the rotational margin: (i) fields that were never planted to monoculture (i.e., always rotated between corn and soybeans) and (ii) fields that were planted to monoculture at least once. For the other-crop margin, we estimate the model separately, within each soil-climatic regime, for (i) fields that transitioned between corn or soybeans and other crops and (ii) fields that always planted corn or soybeans. ${ }^{11}$

\footnotetext{
${ }^{11}$ Fields that were always planted to other crops are not included in our econometric analysis - that is, we assume that the response to price is zero for fields that were always planted to other crops during our sample period.
} 
We assume that the Markov chains are reducible for those fields where certain transitions were never observed. At the rotational margin, for fields that were never planted to monoculture we impose the identifying restrictions $\Phi_{i t}^{c c}=0$ and $\Phi_{i t}^{s c}=1$. At the other-crop margin, for fields that were always planted to corn or soybeans we impose the identifying restrictions $\operatorname{Prob}\left(c b_{i t}=1 \mid c b_{i, t-1}=1\right)=1$ and $\operatorname{Prob}\left(c b_{i t}=1 \mid c b_{i, t-1}=0\right)=1$. Thus, the short-run and long-run marginal effects of price are zero for these fields. This conditional estimation approach is like the conditional likelihood approach used in discrete-choice models in that the parameters are only identified for fields that changed states (Heckman, 1981). A similar estimation strategy is used by Bernard and Jensen (2004), who estimate the probability of a firm exporting as a function of whether the firm exported in the previous period.

We estimate cluster-robust standard errors using a bootstrap with 500 replications, where we cluster by year. Clustering by year permits cross-sectional (i.e., spatial) dependence between all of the fields for a given year, but assumes independence between years. The traditional pairs cluster bootstrap performs poorly in settings with relatively few clusters (11, in our case), so we use the fixed-design wild bootstrap advocated by Cameron, Gelbach, and Miller (2008). To implement our bootstrap, we select the residuals from our OLS regressions with probability 0.5 and the negative of the residual with probability 0.5 . The assignment of the residual or the negative of the residual is the same for all observations within a given year, which preserves any unmodeled spatial dependence. We then generate bootstrap samples of the dependent variable by adding the resampled residuals to the original predicted values from the regression. We report standard errors that are the standard deviation of bootstrap replications after removing replications where the relative difference between the short-run and long-run elasticities is greater than 0.99 or less than $-0.99 .{ }^{12}$ Our strategy of trimming the bootstrap replications could bias our standard errors downward. However, these trimmed bootstrap standard errors are of similar magnitude to standard errors calculated in a pooled model with the conventional "sandwich" cluster-robust estimator (see the online appendix).

\footnotetext{
${ }^{12}$ Some bootstrap replications yield a relative difference between the short-run and long-run elasticities, $\frac{\varepsilon_{L R}-\varepsilon_{S R}}{\varepsilon_{L R}}$, that is outside the unit circle. We omit these samples because they are implausible.
} 


\section{Data for Econometric Model}

We report summary statistics of our data in table 1 and provide descriptions of the data sources and construction of the variables in this section. The rotational margin sample includes observations (field-year pairs) that were classified as corn or soybeans in two consecutive years. The other-crop margin sample includes observations that were classified as a crop in two consecutive years and where the field was classified as corn or soybeans at least once during the sample period. See Hendricks, Smith, and Sumner (2014) and their online appendix for more details on the construction of the data.

\subsection{Crop Data and Field Boundaries}

Our crop data come from the Cropland Data Layer (CDL), ${ }^{13}$ which is produced by the National Agricultural Statistics Service (NASS) of the United States Department of Agriculture (USDA). The CDL is an image of an entire state with a crop or land use classification code corresponding to each pixel, where each pixel is less than one acre in size. NASS classifies pixels using data from satellite sensors and performs validation exercises to "ground truth" the data. We use Common Land Unit boundaries in 2007 from the Farm Service Agency to approximate "field" boundaries. We choose points near the centroids of Common Land Units greater than 15 acres as our units of analysis. Our analysis uses crop data in Illinois for the period 1999-2010 and Iowa and Indiana for 2000-2010.

Our empirical analysis uses three crop classifications: corn, soybeans, and other crops (primarily alfalfa and wheat). According to accuracy assessments conducted by NASS, the probability that the CDL correctly classifies corn or soybeans is roughly $95 \%$ on average in these three states. The CDL is less accurate at distinguishing between other crops, so we merge them all into a single category. Our econometric model does not estimate transitions with noncrop land uses because the CDL is less accurate at classifying noncrop land uses.

\footnotetext{
${ }^{13}$ The Cropland Data Layer can be viewed and downloaded at http://nassgeodata.gmu.edu/ CropScape/. For details on the methodology of constructing the Cropland Data Layer see Boryan et al. (2011).
} 
Most of the transitions with noncrop land uses in this region are likely to occur due to changes in enrollment in the Conservation Reserve Program (CRP). We use county-level data on changes in CRP acreage to separately estimate the potential effect on nitrogen losses from changes in CRP enrollment.

\subsection{Expected Crop Prices}

In our econometric model, the right-hand side regressor is the expected effective price prior to planting including per-unit government payments - for which we use the shorthand "expected price." Expected crop prices are the sum of a futures price, an expected basis, and an expected loan deficiency payment. For corn, the futures price is the average price in JanuaryMarch of a December futures contract. For soybeans, the futures price is the average price in January-March of a November futures contract. Futures price data are obtained from the Commodity Research Bureau.

We use the basis in March, prior to planting, as the expectation for the harvest basis. The basis in March provides a reasonable expected basis prior to planting because storage bounds temporal-arbitrage opportunities. To measure the basis, we use spot prices in March of each year for 93 market locations in the three states for corn and 90 locations for soybeans from GeoGrain. We interpolate to every point in the dataset using inverse distance weighting.

The U.S. government provided a subsidy for corn and soybeans when market prices were low - called loan deficiency payments - throughout the data period. The loan deficiency payment equals the difference between a county-specific loan rate and the posted county price - the government's measure of the local market price-times the farmer's production, but is only triggered when the posted county price falls below the county-specific loan rate. We assume that the loan rate truncates the price distribution from below. We use the formula for a truncated mean to estimate an expected price that incorporates the possibility

of a loan deficiency payment assuming that the harvest-price distribution has a lognormal conditional distribution where the standard deviation is the implied volatility of options 
contracts. We assume the expected loan deficiency payment is constant across counties and varies only by year. Implied volatility data are from the Commodity Research Bureau. Loan rate and posted county price data are from the Farm Service Agency.

We construct a Laspeyres index of expected corn and soybean prices for the current crop year and a Laspeyres index of expected alfalfa and wheat prices for the analysis of changes between corn and soybeans and other crops. We construct these indices at the county level using the expected crop yield times the crop acreage in 2000 as the weights for expected prices. Expected yield is the prediction from county-specific regressions with a linear trend using NASS county-level data from 1980 to 2010. The expected alfalfa price, for which no futures market exists, is the average January-March price in Iowa. ${ }^{14}$ The expected wheat price is the sum of a futures price and an expected loan deficiency payment.

\subsection{Soil-Climatic Regimes}

Construction of the soil-climatic regimes is as follows. First, we use Major Land Resource Areas (MLRAs) from the Natural Resources Conservation Service (NRCS) to define groups of fields. NRCS defines Major Land Resource Areas as areas with similar soils, climate, and land uses. There are 33 MLRAs in the three states, but some of these MLRAs are near the state borders and contain little area in our study region. We combine small MLRAs with neighboring MLRAs with similar characteristics to create 24 groups. We further divide these groups according to soil taxonomy classifications, which are available in the Soil Survey Geographic (SSURGO) database from NRCS. Soil taxonomy classifies soils by general characteristics of the soil with six classification hierarchies: order, sub-order, great-group, sub-group, family, and series. There are over 1,000 unique classifications in the region, but we do not have enough data to estimate separate coefficients for this many classifications. Instead, we divide MLRAs by the soil taxonomy order only if there are greater than 25,000 observations in the order and greater than 25,000 observations in the remaining orders. We

\footnotetext{
${ }^{14}$ Monthly price data for our sample period are only available for Iowa. We obtain these data from NASS.
} 
continue in a similar fashion to divide orders by sub-orders, great-groups, and sub-groups while ensuring 25,000 observations in each of our soil-climatic regimes. ${ }^{15}$ This procedure results in 108 soil-climatic regimes.

\subsection{Other Soil and Weather Data}

Data on soil texture (percent clay, percent silt, and percent sand) and slope are from the SSURGO database. County-level data on the share of cropland that is irrigated are from the 2007 Census of Agriculture. Precipitation in April and May for each year are from PRISM (Parameter-elevation Regressions on Independent Slopes Model). PRISM interpolates precipitation data to create a grid of monthly precipitation with a resolution of about 2.5 miles x 2.5 miles. PRISM data are USDA's official climatological data. We include a dummy variable in our regressions that indicates if April-May precipitation was greater than the 75th percentile in the three states during our sample period since heavy rainfall can delay corn planting and prompt substitution to soybeans.

\section{SWAT Model}

The SWAT model is a continuous-time, distributed-parameter, hydrologic and water quality model developed by USDA ARS (Arnold et al., 1998). Weather, topography, soil properties, landcover and land management inputs are used by SWAT to simulate hydrologic, soil erosion, sediment, nutrient, pesticides, and bacteria yield responses; this study focuses on the hydrologic and nutrient model components. SWAT delineates a watershed into subwatersheds, which are further divided into hydrologic response units (HRUs) that represent areas within a subwatershed having similar landcover, soil, and slope (Gassman et al., 2007; Daggupati et al., 2011). SWAT simulates field-scale processes at the HRU scale, aggregates HRU outputs at the subwatershed scale, and routes the surface runoff along with dissolved and suspended constituents via channels to the watershed outlet. In this study, we use SWAT

\footnotetext{
${ }^{15}$ We complete this process with the dataset used to estimate the other-crop margin response, so fields in the other-crop and rotational margin datasets belong to the same soil-climatic regimes.
} 
results for nitrogen losses at the edge-of-the-field in order to merge spatially-explicit results from SWAT with the results from the econometric model.

Details on the data and methods used to configure the SWAT model are provided in the online appendix. Importantly, we differentiate fertilizer use by crop rotation and also account for tile drainage. The SWAT model was run using the detailed climate, soils, topography, land use, and land management data without hydrologic calibration, as demonstrated by Srinivasan, Zhang, and Arnold (2010) in the same region with reasonable results. HRUlevel results were obtained by running the SWAT model for a 10-year period with a 3-year "warm-up" period (Jan 1999 to Dec 2011) separately for each of the following land uses : continuous corn, continuous soybeans, corn-soybean rotation, wheat, oats, alfalfa, and the Conservation Reserve Program (CRP). These runs produced the nutrient losses that would result from each crop rotation or land use on each land parcel. The corn-soybean rotation was simulated twice - with corn in even years and with corn in odd years. Grassland in CRP was simulated as Indian-grass following Jha et al. (2010). Ten-year average annual nitrogen losses from each HRU across the entire modeled area were determined for the following land uses: corn after corn, corn after soybeans, soybeans after corn, soybeans after soybeans, wheat, oats, alfalfa, and CRP. Nitrogen losses from corn after soybeans represent the average nitrogen losses during years of corn production in the corn-soybean rotation, and similarly for soybeans after corn. The HRU-level results were used to represent field-level total nitrogen loss for each soil, slope, and land use. The field-level nitrogen loss results for each land use throughout the study area were georeferenced for merging with the estimates from the econometric model.

\section{Results}

First, we report results from the econometric model that is estimated using all of the crop data in Iowa, Illinois, and Indiana. Next, we report results from the SWAT model, which is developed for four watersheds that cover most of the area in the three states. Then we 
integrate the econometric and SWAT results to estimate the effect of crop prices on nitrogen losses for the region that includes results from both models.

\subsection{Crop Rotation Response to Price}

Table 2 reports aggregate price elasticities for corn and soybean acreage response to price. ${ }^{16}$ Aggregate price elasticities are the average marginal effects of prices across all observationsweighted by the size of each field - converted into elasticity form. The rotational, other crop, and total marginal effects of price are calculated using equation (15). The bottom row of table 2 reports the relative difference in the short-run $\left(\varepsilon_{S R}\right)$ and long-run $\left(\varepsilon_{L R}\right)$ elasticities, which is analogous to the coefficient on a single lagged dependent variable in a linear regression.

Panel A of table 2 reports corn acreage price elasticities. The response at the other crop margin is minimal - that is, very little change in corn and soybean acres occurs through changes with other crops in response to changes in expected prices. However, there is substantial response at the rotational margin. In total, a 10\% increase in the expected price of corn results in a $4.0 \%$ increase in corn acreage in the short run and a $2.9 \%$ increase in the long run (column 3). The cross-price elasticity for corn acreage is negative and large relative to the own-price elasticity. Panel B of table 2 reports soybean acreage price elasticities. In the short run, a $10 \%$ increase in the expected price of soybeans results in a $3.6 \%$ increase in soybean acreage and a $2.6 \%$ increase in the long run. The magnitude of the cross-price elasticity for soybean acreage is actually larger than the own-price elasticity. Corn and soybean acreage may be more responsive to changes in corn prices than soybean prices because soybeans are grown largely to capture rotational benefits. The response to a price shock is $38 \%$ larger in the short run than in the long run (bottom row of table 2) because some fields that changed crop rotations due to a price shock switch back to the previous crop in order to continue the new rotation.

\footnotetext{
${ }^{16}$ These results differ very slightly from those in table 2 in Hendricks, Smith, and Sumner (2014) because of the minor specification differences noted in footnote 6 .
} 
Table 3 reports aggregate elasticities of crop rotation responses to expected crop prices. We report crop rotation price elasticities conditional on corn or soybeans being planted since the other crop margin response is negligible. The short-run and long-run marginal effects of price on corn after corn are calculated as in equations (10) and (11) and the marginal effects of price for the corn-soybean rotation and soybeans after soybeans are calculated similarly from derivatives of (8) and (9).

An increase in the expected price of corn increases the probability of planting corn after corn and decreases the probability of planting a corn-soybean rotation and planting soybeans after soybeans (table 3). The effect of an increase in the expected price of soybeans is the opposite sign for all rotations. Although theory does not give an expected sign for the effect of price on a corn-soybean rotation, it is not surprising that increases in the expected price of corn decrease the probability of a corn-soybean rotation since corn after corn is more prominent than soybeans after soybeans. Consistent with our predictions in Section 2.1, the short-run elasticity is about $30 \%$ smaller than the long-run elasticity.

Elasticities of a corn-soybean rotation are substantially smaller than elasticities for corn after corn and soybeans after soybeans (table 3) for two reasons. First, there is a larger probability of planting a corn-soybean rotation on average, so relative changes are smaller. Second, a decrease in the probability of a corn-soybean rotation from switching to corn after corn is partly offset by an increase in the probability of a corn-soybean rotation by switching from soybeans after soybeans.

Figure 1 shows maps of the observed crop transitions and results from the econometric model (a color figure is available in the online version of this article). The maps only show results where results from the SWAT model intersect the results from the econometric model. We developed SWAT models for four watersheds that include most of the three states, but western Iowa is not included. Panel A of figure 1 shows the crop transitions that were observed from 2009 to 2010. In the first map, red indicates fields that were corn in 2009 and corn in 2010 and green indicates fields with any other crop transition. Corn after corn 
is planted more in northern Illinois, west-central Illinois, northeastern Iowa, and northwest Indiana. In the second map, purple indicates fields that were either corn in 2009 and soybeans in 2010 or soybeans in 2009 and corn in 2010. In the third map, blue indicates fields that were soybeans in 2009 and soybeans in 2010. Soybeans after soybeans are planted more often in southern Illinois and eastern Indiana.

Panel B of figure 1 shows the long-run probability of planting each crop rotation predicted from the econometric model using equations (7)-(9). In the first map, darker red corresponds to a greater probability of planting corn after corn. In the second map, darker purple corresponds to a greater probability of a corn-soybean rotation. In the third map, darker blue corresponds to a greater probability of planting soybeans after soybeans. The predicted probabilities in panel B correspond well to the spatial concentration of observed transitions in panel A. In the online appendix, we compare average predicted probabilities at the county level to the average observed crop transitions. The econometric model performs well at predicting the prevalence of each crop sequence.

Panel $\mathrm{C}$ of figure 1 shows the long-run change in probability of each crop rotation from a $\$ 1$ increase in the expected price of corn. Our estimates of the marginal effects of price vary spatially because we estimate the econometric model separately for soil-climatic regimes. In the first map, darker red corresponds to areas with a greater increase in the probability of corn after corn from an increase in the price of corn. A marginal effect of 0.2 indicates an increase in the long-run probability of planting corn after corn by 0.2 from a $\$ 1$ per bushel increase in the expected price of corn. Corn after corn is more likely to increase in Iowa, north and central Illinois, and northwest Indiana from an increase in the price of corn.

In the second map of panel $\mathrm{C}$, darker blue indicates a larger increase in the long-run probability of planting a corn-soybean rotation and darker red indicates a larger decrease in the long-run probability of planting a corn-soybean rotation from an increase in the price of corn. In other words, blue regions are those where an increase in the price of corn primarily causes a shift from soybeans after soybeans to a corn-soybean rotation and red regions are 
those where an increase in the price of corn primarily causes a shift from a corn-soybean rotation to corn after corn. In the third map of panel $\mathrm{C}$, darker blue indicates a larger decrease in the probability of planting soybeans after soybeans from an increase in the price of corn. The maps give a rich form of spatial heterogeneity of crop rotation response to price that would not likely be captured by spatial regimes from a few land capability classifications or by a spatial econometric model in which the researcher defines a spatial weights matrix.

\subsection{Nitrogen Losses from Land Use Change}

Table 4 gives the average nitrogen losses from the edge of fields as predicted by the SWAT model for different land uses. Nitrogen losses are the sum of nitrate and organic nitrogen losses. Corn after corn generates the largest nitrogen losses, primarily because more fertilizer is applied to corn after corn since there is no nitrogen carry-over from a previous soybean crop. We find a negligible difference in nitrogen losses between corn after soybeans, soybeans after corn, and soybeans after soybeans. Soybean cultivation generates large nitrogen losses relative to wheat, oats, and alfalfa likely due to greater nitrogen availability as well as other factors, such as the timing of storms relative to surface cover at that time of year. Nitrogen losses from CRP are minimal. Therefore, conversion from CRP to crop production results in a large increase in nitrogen losses. The standard deviations of nitrogen losses are relatively large, indicating substantial variation among fields across the region.

It is difficult to compare our estimates of nitrogen losses with results from field experiments since nitrogen losses depend on a large number of factors including weather, fertilizer application rates, presence of tile drainage, and soils. Still, our estimates of nitrogen losses are generally consistent with those reported by Sawyer and Randall (2008), who survey a number of results from field experiments. We also found our estimates to fall within the range of other modeling studies in the region. For example, Gowda, Mulla, and Jaynes (2008) re-

port annual average measured (23.2 lbs/acre) and modeled (21.6 lbs/acre) nitrate-N losses in a central-Iowa watershed with 90 percent of the cropland planted to a corn-soybean rotation 
close to our values for corn after soybeans and soybeans after corn. Sogbedji and McIsaac (2006) report annual average measured (37.9 lbs/acre) and modeled (37.6 lbs/acre) riverine nitrate- $\mathrm{N}$ in an Illinois watershed with 85 percent of the cropland planted to a corn-soybean rotation close to our values for corn after corn.

Figure 2 shows the difference in nitrogen losses if corn after corn is planted rather than a corn-soybean rotation, where we calculate the annual nitrogen loss from a corn-soybean rotation as the average of the nitrogen losses from planting corn after soybeans and soybeans after corn (a color figure is available in the online version of this article). Darker red areas indicate areas where conversion from a corn-soybean rotation to corn after corn results in greater increases in nitrogen losses - in other words, areas of greater environmental sensitivity to land use change. For example, a value of 18 indicates that planting corn after corn results in $18 \mathrm{lbs} /$ acre more nitrogen losses than planting a corn-soybean rotation on average.

\subsection{Nitrogen Losses in Response to Crop Prices}

First we evaluate the aggregate change in nitrogen losses with respect to changes in crop prices, then we examine the spatial distribution of these losses. We exclude the effect of CRP conversions on nitrogen losses in this section, but present estimates of a plausible magnitude for the effect of CRP conversions in section 5.5. Table 5 reports aggregate elasticities of nitrogen losses with respect to changes in corn and soybean prices.

In order to develop estimates of the elasticities, we calculate average nitrogen losses from the edge of fields $(N \bar{N})$ as

$$
\bar{N} L=\sum_{i} \frac{a_{i}}{A} \sum_{m} \Pi_{i}^{m} N L_{i}^{m}
$$

where $a_{i}$ is the acres of field $i, A$ is the total acreage of all fields in our sample, $\Pi_{i}^{m}$ is the

predicted probability of land use $m$ from the econometric model, and $N L_{i}^{m}$ is the nitrogen loss of land use $m$ from the SWAT model. We consider the following land uses: corn after corn, corn after soybeans, soybeans after corn, soybeans after soybeans, wheat, oats, and alfalfa. The SWAT model gives nitrogen losses for each of these land uses. Our econometric 
model gives the probability of each transition between corn and soybeans and the probability of other crops. To estimate the probability of wheat for field $i$, we multiply the probability of "other crops" by the proportion of observations classified as wheat on field $i$ for those observations classified as "other crops" - and similarly for oats and alfalfa. If the crop data indicate an "other crop" besides wheat, oats, or alfalfa, then we use the average nitrogen loss of wheat, oats, and alfalfa. ${ }^{17}$

Next, we calculate the elasticity of nitrogen losses with respect to the price of crop $j$ from equation (16) as

$$
\frac{\partial \bar{N} L}{\partial p^{j}} \frac{\bar{p}^{j}}{N \bar{N} L}=\sum_{i} \frac{a_{i}}{A} \sum_{m} \frac{\partial \Pi_{i}^{m}}{\partial p^{j}} N L_{i}^{m} \frac{\bar{p}^{j}}{\bar{N} L} .
$$

Short-run nitrogen loss elasticities are obtained by using short-run land use marginal effects of price in (17), and similarly for long-run price elasticities.

Standard errors for the nitrogen loss elasticities are generated within the wild bootstrap procedure used in the econometric model. For each set of resampled dependent variables, we estimate the aggregate nitrogen loss elasticity in equation (17). We are unaware of any previous research that has integrated results from a biophysical model into a bootstrap procedure. ${ }^{18}$ An important caveat to our standard errors is that they do not incorporate any uncertainty in the estimates from the SWAT model and thus overestimate the precision of our estimates for that reason.

Column (1) of table 5 reports our preferred estimates of the nitrogen loss elasticities excluding CRP conversions. A $10 \%$ increase in the expected price of corn results in a $0.50 \%$ increase in aggregate nitrogen losses from fields in the short run and a $0.76 \%$ increase in aggregate nitrogen losses from fields in the long run. Nitrogen losses are positively related to

\footnotetext{
${ }^{17}$ Observations classified as a crop other than corn, soybeans, wheat, oats, or alfalfa represents less than $0.5 \%$ of land use in our sample.

${ }^{18}$ Our method is feasible because we use edge-of-field nitrogen loss estimates from SWAT so these estimates are constant for each bootstrap replication. A common approach in integrated models is to simulate land use scenarios and run SWAT for the particular land use scenario. Estimating standard errors for this alternative approach would require running SWAT for each land use scenario from each bootstrap replication, which is not feasible.
} 
the expected price of corn and negatively related to the expected price of soybeans primarily due to the response of corn-after-corn acreage to price shocks.

The nitrogen loss response to a price shock is $34 \%$ smaller in the short run than in the long run (bottom row of table 5). This result arises because nitrogen losses are largest from fields with consecutive years of corn, and corn-after-corn acreage responds to a price shock less in the short run than in the long run (see the discussion of results in table 3). Another reason for this difference is that the long-run response exceeds the short-run response at the othercrop margin for corn and soybean acreage. Changes at the other-crop margin give greater changes in nitrogen losses because there is a large difference in nitrogen losses from corn or soybeans versus other crops. However, even if we estimate the nitrogen loss elasticities using only rotational margin responses, the short-run response is still $34 \%$ smaller than the longrun response (results not reported). Thus, the dynamics of corn-after-corn acreage response to price are the main driver of the dynamics of nitrogen losses.

Columns (2) and (3) of table 5 evaluate the importance of modeling the spatial heterogeneity of coefficients for estimates of aggregate nitrogen loss elasticities. Column (2) reports nitrogen loss elasticities calculated by imposing the same price response on all fields. The econometric model is the same in column (2) as column (1), but in column (2) we generate the nitrogen loss estimates using the average crop rotation response to price rather than fieldspecific responses. Nitrogen loss elasticities are very similar using the average response to price. This result arises because the correlation is small between the corn-after-corn acreage response to price and the increase in nitrogen losses from planting corn after corn rather than a corn-soybean rotation.

Column (3) of table 5 reports nitrogen loss elasticities if we impose common coefficients for all fields (i.e., pooling) in the econometric estimation. For the pooled estimator, we estimate linear Markov transition probabilities, but estimate a single model for all fields. Pooled estimates are biased because unobserved heterogeneity is confounded with the dynamics and because heterogeneous responses to autocorrelated prices are confounded with 
dynamics (Pesaran and Smith, 1995). Short-run marginal effects of price are smaller for the pooled estimator so nitrogen loss elasticities are smaller in column (3) than column (1). The standard errors are much larger for the pooled estimates in column (3) because the econometric model in column (1) includes substantially more control variables-soil-climatic regime fixed effects and interactions between soil-climatic regimes and all other controls (see the supplementary appendix for more discussion on standard errors). The difference between the short-run and long-run price elasticities is also slightly smaller with the pooled estimator (bottom row of table 5). In summary, the results in table 5 indicate that modeling spatial heterogeneity is important for estimating the aggregate nitrogen loss elasticity primarily because ignoring the heterogeneity induces bias in average econometric estimates.

Figure 3 shows maps of the estimated response of nitrogen losses to changes in prices (a color figure is available in the online version of this article). ${ }^{19}$ The map on the left shows the change in nitrogen losses (lbs/acre) from a $\$ 1 /$ bushel increase in the price of corn, ceteris paribus, where darker red indicates a larger increase in nitrogen losses. The map on the right corresponds to a change in the price of soybeans, where darker blue indicates a larger decrease in nitrogen losses.

The results in the left map of figure 3 reveal "hotspots" where nitrogen losses are likely to increase substantially more when the price of corn increases. Notable hotspots occur in northeast Iowa, northern Illinois, and northern Indiana. Water quality in these areas may be of particular concern when corn prices increase. The right map of figure 3 indicates that these same regions often have the largest decrease in nitrogen losses when soybean prices increase.

The hotspots in our analysis identify areas in which the payoffs to conservation efforts are likely to be the largest because nitrogen losses are more responsive to financial incentives. Policymakers would like to focus efforts where environmental outcomes are more responsive

\footnotetext{
${ }^{19}$ No results are estimated for western Iowa because we only develop the SWAT model for the four watersheds that cover most of the three states.
} 
to financial incentives because land use is more responsive to financial incentives or land use change has a larger environmental impact.

\subsection{Robustness Checks}

We report the results from several robustness checks in the supplementary online appendix. In all of the robustness checks we alter the specification of the econometric model and report estimates of corn acreage and nitrogen loss elasticities.

Given that our primary source of identification is the variation in prices between years and from only 11 years of data, our results may be sensitive to the method used to construct expected prices. Therefore, we applied substantial effort to construct expected prices in a reasonable manner for our main results, and we investigated several different methods to check robustness. First, few previous studies include an estimate of the expected basis in estimating the expected price. If we exclude the expected basis from our estimate of the expected price, then we get slightly larger elasticities. Second, we include only time series variation in the expected basis when calculating the expected price. Third, our method of constructing an expected loan deficiency payment using implied volatility is similar to Barr et al. (2011), but differs from most other previous studies. We estimated the expected loan deficiency payment using historical volatility and assuming prices are normally distributed with a method similar to Chavas and Holt (1990). ${ }^{20}$ Finally, we use the futures price trading during only January, only February, or only March. Our preferred estimate averages across all three months. Overall, we obtain similar elasticity estimates.

We also consider several different specifications of our controls to account for anticipated supply shocks that may affect planting decisions and the futures price. We consider different specifications of controls for spring precipitation. Wet spring conditions may reduce corn

\footnotetext{
${ }^{20}$ Implied volatility represents the market's expectation of future volatility and is derived from the prices of options on corn futures, which are traded on the Chicago Mercantile Exchange. In contrast, historical volatility represents the variation from previous years of the futures price trading prior to planting compared to the futures prices trading at harvest. Historical volatility represent a backward-looking measure of the market's volatility.
} 
planting because planting is delayed and dry conditions in spring may reduce corn planting because farmers anticipate a dry growing season. We use two methods to account for this possibility: (i) including a quadratic function of spring precipitation as a control and (ii) including a dummy variable if precipitation was less than the 25 th percentile in addition to the dummy variable for precipitation greater than the 75 th percentile. We also consider including the county-level observed yield shock as a proxy for the anticipated yield shock (see Hendricks, Janzen, and Smith, 2014). Our results are very similar across all specifications of controls so endogeneity of expected prices does not appear to be a major concern in our application. Other robustness checks reported in the appendix include estimating transition probability models using logit rather than linear probability models, using relative prices, estimating second-order Markov transition probabilities, and alternative methods of clustering standard errors.

\subsection{Conservation Reserve Program}

A limitation of our analysis in previous sections is that it does not account for changes in crop acreage due to conversions of noncropland acreage because of limitations of the Cropland Data Layer at identifying such conversions. The primary source of such conversions is land in the Conservation Reserve Program (CRP). This program is administered by the U.S. Department of Agriculture and pays farmers to remove land from crop production and restore it to native habitat under a 10-15 year contract. In this section, we calculate the potential effect of these conversions on nitrogen losses when crop prices increase.

First, we consider a back-of-the-envelope calculation for a corn acreage elasticity due to conversion of CRP (i.e., the CRP margin). CRP enrollment in Iowa, Illinois, and Indiana decreased by about 593 thousand acres from 2007 to 2013 (compared to roughly 30 million acres of corn). Assuming that $55 \%$ of this land was converted to corn production (and $45 \%$ to soybeans) would result in roughly a $1.1 \%$ increase in corn acreage. During this period 
corn and soybean prices increased roughly $60 \%$ implying an acreage elasticity of about 0.018 at the CRP margin (not holding constant the price of soybeans).

Although the effect of CRP conversions on corn acreage is small relative to the total corn acreage elasticity, the effect on nitrogen losses is likely much larger relative to the nitrogen loss elasticities in table 5 because nitrogen losses from CRP land are much smaller compared to land planted to corn. The increase in nitrogen losses due to CRP conversions relative to total nitrogen losses in the region $(A \times N L)$ is calculated as follows:

$$
\frac{\sum_{j}\left[\frac{\Delta C R P_{c}}{\text { Grass }_{c}} \times \text { acres }_{j} \times\left(N L_{j}^{C R P}-N L_{j}^{\text {crop }}\right)\right]}{A \times \bar{N} L},
$$

where $j$ denotes HRUs (SWAT's delineation of land within a subwatershed) classified as grassland or rangeland. The change in CRP acreage from 2007 to 2013 for county $c$ is obtained from the Farm Service Agency and is denoted as $\Delta C R P_{c}$. The total area in county $c$ classified as grassland by the National Land Cover Database is denoted Grass. We do not know where CRP conversions occurred within a county so we assume an equal probability $\left(\frac{\triangle C R P_{c}}{\text { Grass }_{c}}\right)$ of each HRU classified as grassland or rangeland converting to cropland. We multiply the probability of an HRU converting to cropland by the acres of the HRU $\left(\right.$ acres $\left._{j}\right)$ and the change in nitrogen losses from converting $\left(N L_{j}^{C R P}-N L_{j}^{c r o p}\right)$. The nitrogen losses of crop production $\left(N L_{j}^{\text {crop }}\right)$ are the average nitrogen losses of corn after corn, corn after soybeans, soybeans after corn, and soybeans after soybeans weighted by prevalence of each transition observed within the county.

The calculation described above indicates that nitrogen losses increased roughly $0.98 \%$ from 2007 to 2013 due to CRP conversions. Corn and soybean prices both increased roughly $60 \%$, implying a nitrogen loss elasticity of 0.016 with respect to the price of corn and soybeans. Assume that the nitrogen loss elasticity with respect to the price of corn (holding constant the price of soybeans) is $0.008(0.016 / 2)$ and similarly for the elasticity with respect to the price of soybeans. These calculations increase our estimated nitrogen loss elasticies by 
10 to $15 \%$. We obtain a total long-run nitrogen loss elasticity with respect to the price of corn of $0.084(0.076+0.008)$ and with respect to the price of soybeans of $-0.045(-0.053+0.008)$. Conversions of CRP are likely to be minimal in the short-run since CRP acreage is under 10-15 year contracts.

We consider these calculations of the effect of CRP conversions on nitrogen losses as useful but not definitive. We also regressed CRP acreage on an index of corn and soybean prices and the average rental payment for CRP (results available in online appendix). The regressions indicated a smaller response to price than our calculations, but our regressions fail to account for the complex effect of contracts. An issue with our calculations in this section is that we ignore changes in the payment rate for enrolling land in CRP, which is a function of federal legislation. The 2008 Farm Bill reduced the cap on CRP acreage from 39.2 million acres (although only 36.8 million acres were enrolled in 2007) to 32 million acres. ${ }^{21}$ We do not attempt to estimate the effect of legislation on CRP enrollment, nor discuss the causal relationship between the legislation and crop prices.

\section{Application to Ethanol Production and Water Quality}

We illustrate the economic and environmental significance of our nitrogen loss elasticities by utilizing them to estimate the effect of a policy that distorts crop prices - the U.S. ethanol mandate - on nitrogen losses. In this section, we first use our elasticities to develop estimates of the effects of ethanol production and then we compare our assessment with results from previous literature.

\subsection{Estimates of the Effect of Ethanol Production}

We assume that every billion gallons of ethanol increases the price of corn by 5.5 percent and increases the price of soybeans 3.5 percent. This assumption is broadly consistent with recent studies. Roberts and Schlenker (2013) estimate that the 2009 Renewable Fuel Standard (11

\footnotetext{
${ }^{21}$ The 2014 Farm Bill further reduces the cap to 24 million acres by 2017.
} 
billion gallons of ethanol) has increased the price of grains by 20 percent. They also estimate a multicrop system of supply and demand and estimate that the Renewable Fuel Standard increased the price of corn roughly $50-60 \%$ and the price of soybeans roughly $43 \%{ }^{22}$ Carter, Rausser, and Smith (2013) estimate that the 2007 expansion of the Renewable Fuel Standard in the United States (an additional 5.5 billion gallons of ethanol) increased the price of corn by 34 percent.

Using the nitrogen loss elasticities shown in column (1) of table 5, a 5.5 percent increase in the price of corn and 3.5 percent increase in the price of soybeans leads to a 0.23 percent increase in nitrogen losses from Iowa, Illinois, and Indiana in the long run. The associated 95 percent confidence interval is $[0.13 \%, 0.33 \%]{ }^{23}$

We estimate the effect of a billion gallons of ethanol production on the size of the hypoxic zone in the Gulf of Mexico using estimates from Obenour et al. (2012). They develop a regression model that relates the size of the hypoxic zone (measured midsummer) to a normalized metric of water column stratification and the normalized May nitrogen concentration (see equation 13 of Obenour et al., 2012). ${ }^{24}$ We obtain data from the USGS on the May nitrogen loads and stream flow from the Mississippi and Atchafalaya River outlets. The nitrogen concentration is calculated as the load divided by the stream flow. A 0.23 percent increase in nitrogen concentration translates to a $25.0 \mathrm{mi}^{2}\left(64.7 \mathrm{~km}^{2}\right)$ increase in the size of the hypoxic zone according to the regression estimates of Obenour et al. (2012) and the associated 95 percent confidence interval is $\left[14.3 \mathrm{mi}^{2}, 35.7 \mathrm{mi}^{2}\right]$. Our estimate of this confidence interval, however, ignores uncertainty in (i) the SWAT model, (ii) the estimates from Obenour et al. (2012), and (iii) the effect of ethanol on crop prices. Incorporating the effect of CRP as calculated in the previous section, a billion gallons of ethanol production leads to

\footnotetext{
${ }^{22}$ In the two crop system, Roberts and Schlenker (2013) estimate that the Renewable Fuel Standard increased the price of other crops by only $27 \%$.

${ }^{23}$ The confidence interval is estimated using our bootstrap procedure.

${ }^{24}$ Alternative estimates of the relationship between the size of the hypoxic zone and nutrient concentrations are provided by Rabotyagov et al. (2014) and Forrest, Hetland, and DiMarco (2011).
} 
a 0.30 percent increase in nitrogen concentration which translates to a $32.7 \mathrm{mi}^{2}$ increase in the size of the hypoxic zone.

An inherent assumption in this analysis is that reduction in nitrogen delivery to the Gulf is proportional to reduction in edge-of-field nitrogen losses used to develop table 5. This assumption is justified on the basis of the relatively small fraction of in-stream removal for tile-drained watersheds with high nutrient concentrations during periods of high flows (Dale et al., 2007; Royer, David, and Gentry, 2006). Royer, David, and Gentry (2006) reported $97 \%$ of the nitrate-nitrogen flows in upper-mid-western agricultural streams occurred when flows were above median values (such as in May as used by Obenour et al. (2012)), when denitrification has little effect on nitrate-nitrogen retention.

Our analysis also ignores changes in the crop price basis due to ethanol production. It may be that local prices increase relatively more in areas close to ethanol production facilities. For example, McNew and Griffith (2005) estimate that corn prices were $\$ 0.125 /$ bushel higher near ethanol plants. Towe and Tra (2013) estimate larger land values near ethanol plants indicating an expected long-run change in the local cash price while Blomendahl, Perrin, and Johnson (2011) find little evidence of an effect on land values. The effect of ethanol production on the local basis is likely to be small relative to the effect on world prices, but would certainly affect the spatial distribution of nitrogen losses due to ethanol production. ${ }^{25}$

\subsection{Comparison to Previous Estimates}

We compare our methods and results to three previous studies that link ethanol production and nitrogen losses in the central Corn Belt. Our methodology improves upon Donner and Kucharik (2008) by integrating an economic model with the biophysical model. Donner and Kucharik (2008) report much larger effects of the increase in the use of corn for ethanol on nitrogen losses than we do. They estimate that producing 15 billion gallons of ethanol by 2022 would increase nitrogen losses by 10-18 percent. Their 15 billion gallon scenario assumes

\footnotetext{
${ }^{25}$ For example, assume ethanol production has increased world corn prices by $50 \%$ from a baseline price of $\$ 3.00$. An increase in the local basis of $\$ 0.125$ is small relative to an increase in the world price of $\$ 1.50$.
} 
that all of the additional ethanol to meet the mandate is produced using corn produced in the United States. This assumption overstates the effect of the mandate because the shift in corn demand due to additional ethanol production increases the price of corn. The movement to a new market equilibrium causes a movement along the demand curve - as quantity demanded for other uses decreases - and a movement along the supply curve globally. Donner and Kucharik (2008) show maps of nitrogen losses under different scenarios, however, they use state-level expected corn planting in 2007 to allocate expanded corn acreage spatially. In this paper, we use spatially explicit econometric estimates to indicate where the expansion of corn acreage is likely to occur.

Secchi et al. (2011) simulate nitrogen losses under different price scenarios using a programming model of cropping decisions and the SWAT model for water quality outcomes. In order to estimate implied nitrogen loss elasticities from their results, we examine two of their scenarios that have a similar price of soybeans. Between scenarios 2 and 3 in Secchi et al. (2011), the price of corn increases from $\$ 5.00$ per bushel to $\$ 5.20$ per bushel (4.0 percent increase) while the price of soybeans decreases from $\$ 12.50$ per bushel to $\$ 12.48$ per bushel $(0.2$ percent decrease). Their simulations suggest that total nitrogen losses increase 1.4 percent between these two scenarios, implying a nitrogen loss elasticity with respect to the price of corn of roughly 0.35 compared to our estimate of 0.076 in the long run. Their nitrogen loss elasticity is substantially larger than our estimate primarily because they estimate a much larger corn acreage response to price than we find. Their results indicate that corn acreage increases 6.7 percent between these two scenarios, implying a corn acreage elasticity with respect to the price of corn of roughly 1.68 compared to our estimate of 0.29 in the long run. Therefore, it appears that the main difference between our results and those of Secchi et al. (2011) arises because we estimate acreage response to price using an econometric model with observed crop changes whereas they use a programming model with a very high implied price elasticity. 
Langpap and $\mathrm{Wu}$ (2011) estimate econometric land use models for two groups of states in the Midwestern United States. They estimate a short-run own-price corn acreage elasticity of 0.246 at the rotational margin - smaller than our estimate of 0.40 . This is consistent with our result that pooling bias results in an underestimate of the elasticity. ${ }^{26}$ However, they estimate an elasticity of cropland acreage with respect to the price of corn of 0.059 for the Corn Belt - much larger than our estimate. The likely reason for the difference from our results is that they use data from the period 1979-1997 when cropland acreage in the U.S. was heavily affected by government programs. Prior to the 1996 FAIR Act, government set-aside programs restricted acreage of program crops, affecting acreage at the rotational and noncropland margins. Lubowski et al. (2006) note that land area in set-aside programs during this period was inversely related to prices which is consistent with market supply response or with government policy to remove acreage from production when prices are low. Thus, the large response of noncropland acreage to price estimated by Langpap and Wu (2011) is likely a result of their data period. Langpap and Wu (2011) simulate several price scenarios that indicate increases in nitrogen losses of roughly 11-30 percent. None of their scenarios represent the effect of a particular policy. ${ }^{27}$ The likely reason that their simulations include much larger effects on nitrogen losses is due to the substantial conversions between crop uses and annual land idling in their data period.

\section{Conclusion}

We estimate the effect of crop prices on both aggregate nitrogen losses and the spatial heterogeneity of these nitrogen losses. Our estimate of the aggregate long-run nitrogen loss elasticity with respect to the price of corn is 0.076 and the long-run nitrogen loss elasticity with respect to the price of soybeans is -0.053 for most of Iowa, Illinois, and Indiana. These elasticity estimates do not include the effect of CRP conversions on nitrogen losses. Some

\footnotetext{
${ }^{26}$ Remarkably, our pooled estimate of the short-run own-price corn acreage elasticity is 0.25 (pooled acreage elasticities are not reported).

${ }^{27}$ Langpap and $\mathrm{Wu}$ (2011, p. 158) recognize this limitation of their scenarios.
} 
simple calculations for the effect of CRP indicate that the corresponding total nitrogen loss elasticities (i.e., including the effect of CRP) are 0.084 for the price of corn and -0.045 for the price of soybeans. We create maps that indicate the regions that are likely to see a larger change in nitrogen losses due to changes in crop prices.

Our results illustrate the importance of modeling the dynamics and spatial heterogeneity of crop production for estimates of marginal environmental damages. Incorporating dynamics is important because rotations are a common feature of crop production and an increase in monoculture may have negative environmental impacts. We also find in our application that estimates of aggregate marginal damages are underestimated if the econometric model ignores spatial heterogeneity due to the bias in dynamic econometric models. Incorporating spatial heterogeneity is also important for assessing where marginal damages are largest.

Our elasticity estimates suggest that a billion gallons of ethanol production increases the size of the hypoxic zone by $25 \mathrm{mi}^{2}$ on average - assuming that a billion gallons of ethanol production increases the price of corn by 5.5 percent and increases the price of soybeans 3.5 percent. Including the effect of CRP, a billion gallons of ethanol production may increase the size of the hypoxic zone by $33 \mathrm{mi}^{2}$ on average. So although we estimate that nitrogen losses are highly inelastic with respect to crop prices, the absolute losses can still be large.

While our estimates represent an improvement to previous literature, several caveats to our estimates are warranted. First, crop acreage expansion due to the conversion of CRP or other grasslands are likely to be larger in other regions within the Mississippi River Basin, which would produce a larger effect on the hypoxic zone. Second, we do not estimate the response of fertilizer use or management practices to expected crop prices due to data limitations. We may underestimate the change in nitrogen losses if higher crop prices increase fertilizer use or tile drainage. ${ }^{28}$ On the other hand, we may overestimate the change in nitrogen losses if higher crop prices lead to increased adoption of conservation practices (Miranowski, 1984). Third, although our paper advances the literature by incorporating

\footnotetext{
${ }^{28} \mathrm{An}$ anonymous reviewer noted that there is evidence tile drainage has expanded in recent years and larger, more efficient tiles have been installed on previously tiled land.
} 
econometric uncertainty into the results, future work could also incorporate uncertainty from the biophysical model. 


\section{References}

Arbuckle, K.E., and J.A. Downing. 2001. "The Influence of Watershed Land Use on Lake N:P in a Predominantly Agricultural Landscape." Limnology and Oceanography 46:970-975.

Arnold, J.G., R. Srinivasan, R.S. Muttiah, and J.R. Williams. 1998. "Large Area Hydrologic Modeling And Assessment Part I: Model Development." Journal of the American Water Resources Association 34:73-89.

Barr, K.J., B.A. Babcock, M.A. Carriquiry, A.M. Nassar, and L. Harfuch. 2011. "Agricultural Land Elasticities in the United States and Brazil." Applied Economic Perspectives and Policy 33:449-462.

Bernard, A.B., and J.B. Jensen. 2004. "Why Some Firms Export." Review of Economics and Statistics 86:561-569.

Blomendahl, B.H., R.K. Perrin, and B.B. Johnson. 2011. "The Impact of Ethanol Plants on Surrounding Farmland Values: A Case Study." Land Economics 87:223-232.

Boryan, C., Z. Yang, R. Mueller, and M. Craig. 2011. "Monitoring US Agriculture: The US Department of Agriculture, National Agricultural Statistics Service, Cropland Data Layer Program." Geocarto International, pp. 1-18.

Cameron, A.C., J.B. Gelbach, and D.L. Miller. 2008. "Bootstrap-Based Improvements for Inference with Clustered Errors." Review of Economics and Statistics 90:414-427.

Carter, C.A., G. Rausser, and A. Smith. 2013. "Commodity Storage and the Market Effects of Biofuel Policies." Working paper, Available at http://asmith.ucdavis.edu.

Chavas, J.P., and M.T. Holt. 1990. "Acreage Decisions under Risk: The Case of Corn and Soybeans." American Journal of Agricultural Economics 72:529-538. 
Cho, S.H., J.M. Bowker, and W.M. Park. 2006. "Measuring the Contribution of Water and Green Space Amenities to Housing Values: An Application and Comparison of Spatially Weighted Hedonic Models." Journal of Agricultural and Resource Economics 31:485-507.

Daggupati, P., K. Douglas-Mankin, A. Sheshukov, P. Barnes, and D. Devlin. 2011. "Fieldlevel Targeting using SWAT: Mapping Output from HRUs to Fields and Assessing Limitations of GIS Input Data." Transactions of the ASABE 54:501-514.

Dale, V., T. Bianchi, A. Blumberg, W. Boynton, D. Conley, W. Crumpton, M. David, D. Gilbert, R. Howarth, C. Kling, R. Lowrance, K. Mankin, J. Meyer, J. Opalauch, H. Paerl, K. Reckhow, J. Sanders, A. Sharpley, T. Simpson, C. Snyder, D. Wright, H. Stallworth, T. Armitage, and D. Wangsness. 2007. "Hypoxia in the Northern Gulf of Mexico: An Update by the EPA Science Advisory Board." EPA-SAB-08-003. EPA Science Advisory Board: Washington, D.C.

Dale, V.H., C.L. Kling, J.L. Meyer, J. Sanders, H. Stallworth, T. Armitage, D. Wangsness, T. Bianchi, A. Blumberg, W. Boynton, et al. 2010. Hypoxia in the Northern Gulf of Mexico, vol. 41. New York, NY: Springer.

Donner, S.D., and C.J. Kucharik. 2008. "Corn-based Ethanol Production Compromises Goal of Reducing Nitrogen Export by the Mississippi River." Proceedings of the National Academy of Sciences 105:4513-4518.

Douglas-Mankin, K., R. Srinivasan, and J. Arnold. 2010. "Soil and Water Assessment Tool (SWAT) Model: Current Developments and Applications." Transactions of the ASABE 53:1423-1431.

Duffy, M. 2011. "Continuous Corn versus Corn/Soybeans: Do the Relative Prices Change the Profit Comparison?" Ag Decision Maker Newsletter, Iowa State University. 
Fezzi, C., and I.J. Bateman. 2011. "Structural Agricultural Land Use Modeling for Spatial Agro-Environmental Policy Analysis." American Journal of Agricultural Economics 93:1168-1188.

Forrest, D.R., R.D. Hetland, and S.F. DiMarco. 2011. "Multivariable Statistical Regression Models of the Areal Extent of Hypoxia over the Texas-Louisiana Continental Shelf." Environmental Research Letters 6:045002.

Gassman, P., M. Reyes, C. Green, and J. Arnold. 2007. "The Soil and Water Assessment Tool: Historical Development, Applications, and Future Research Directions." Transactions of the ASABE 50:1211-1250.

Gowda, P.H., D.J. Mulla, and D.B. Jaynes. 2008. "Simulated Long-Term Nitrogen Losses for a Midwestern Agricultural Watershed in the United States." Agricultural Water Management 95:616-624.

Green, C.T., B.A. Bekins, S.J. Kalkhoff, R.M. Hirsch, L. Liao, and K.K. Barnes. 2014. "Decadal Surface Water Quality Trends under Variable Climate, Land Use, and Hydrogeochemical Setting in Iowa, USA." Water Resources Research 50:2425-2443.

Hamilton, J.D. 1994. Time Series Analysis. Princeton, NJ: Princeton University Press.

Heckman, J. 1981. "The Incidental Parameters Problem and the Problem of Initial Conditions in Estimating a Discrete Time-Discrete Data Stochastic Process." In C. Manski and D. McFadden, eds. The Structural Analysis of Discrete Data. Cambridge, MA: MIT Press.

Hendricks, N.P., J.P. Janzen, and A. Smith. 2014. "Futures Prices in Supply Analysis: Are Instrumental Variables Necessary?" American Journal of Agricultural Economics doi: 10.1093/ajae/aau062. 
Hendricks, N.P., A. Smith, and D.A. Sumner. 2014. "Crop Supply Dynamics and the Illusion of Partial Adjustment." American Journal of Agricultural Economics doi: 10.1093/ajae/aau024.

Hennessy, D.A. 2006. "On Monoculture and the Structure of Crop Rotations." American Journal of Agricultural Economics 88:900-914.

Illinois EPA. 2012. "Illinois Integrated Water Quality Report and Section 303(d) List of 2012 Volume I: Surface Water." Bureau of Water, Illinois Environmental Protection Agency: Springfield, IL.

Jayasinghe, S., D. Miller, and J.L. Hatfield. 2012. "Evaluation of Variation in Nitrate Concentration Levels in the Raccoon River Watershed in Iowa." Journal of Environmental Quality 41:1557-1565.

Jha, M.K., C.F. Wolter, K.E. Schilling, and P.W. Gassman. 2010. "Assessment of Total Maximum Daily Load Implementation Strategies for Nitrate Impairment of the Raccoon River, Iowa." Journal of Environmental Quality 39:1317-1327.

Lacroix, A., and A. Thomas. 2011. "Estimating the Environmental Impact of Land and Production Decisions with Multivariate Selection Rules and Panel Data." American Journal of Agricultural Economics 93:784-802.

Landis, D.A., M.M. Gardiner, W. van der Werf, and S.M. Swinton. 2008. "Increasing Corn for Biofuel Production Reduces Biocontrol Services in Agricultural Landscapes." Proceedings of the National Academy of Sciences 105:20552-20557.

Langpap, C., I. Hascic, and J. Wu. 2008. "Protecting Watershed Ecosystems through Targeted Local Land Use Policies." American Journal of Agricultural Economics 90:684-700.

Langpap, C., and J. Wu. 2011. "Potential Environmental Impacts of Increased Reliance on Corn-Based Bioenergy." Environmental and Resource Economics 49:147-171. 
Lichtenberg, E. 1989. "Land Quality, Irrigation Development, and Cropping Patterns in the Northern High Plains." American Journal of Agricultural Economics 71:187-194.

Lubowski, R.N., A.J. Plantinga, and R.N. Stavins. 2008. "What Drives Land-Use Change in the United States? A National Analysis of Landowner Decisions." Land Economics $84: 529-550$.

Lubowski, R.N., M. Vesterby, S. Bucholtz, A. Baez, and M.J. Roberts. 2006. "Major Uses of Land in the United States, 2002." Economic Information Bulletin No. 14, Economic Research Service, USDA.

McNew, K., and D. Griffith. 2005. "Measuring the Impact of Ethanol Plants on Local Grain Prices." Applied Economic Perspectives and Policy 27:164-180.

Miranowski, J.A. 1984. "Impacts of Productivity Loss on Crop Production and Management in a Dynamic Economic Model." American Journal of Agricultural Economics 66:61-71.

Muller, N.Z., and R. Mendelsohn. 2007. "Measuring the Damages of Air Pollution in the United States." Journal of Environmental Economics and Management 54(1):1-14.

Nelson, E., S. Polasky, D.J. Lewis, A.J. Plantinga, E. Lonsdorf, D. White, D. Bael, and J.J. Lawler. 2008. "Efficiency of Incentives to Jointly Increase Carbon Sequestration and Species Conservation on a Landscape." Proceedings of the National Academy of Sciences 105:9471-9476.

Newburn, D.A., and P. Berck. 2006. "Modeling Suburban and Rural-Residential Development Beyond the Urban Fringe." Land Economics 82:481-499.

Obenour, D.R., A.M. Michalak, Y. Zhou, and D. Scavia. 2012. "Quantifying the Impacts of Stratification and Nutrient Loading on Hypoxia in the Northern Gulf of Mexico." Environmental Science \&3 Technology 46:5489-5496. 
Pesaran, M.H., and R. Smith. 1995. "Estimating Long-Run Relationships from Dynamic Heterogeneous Panels." Journal of Econometrics 68:79-113.

Plantinga, A.J. 1996. "The Effect of Agricultural Policies on Land Use and Environmental Quality." American Journal of Agricultural Economics 78:1082-1091.

Rabotyagov, S.S., C.L. Kling, P.W. Gassman, N.N. Rabalais, and R.E. Turner. 2014. "The Economics of Dead Zones: Causes, Impacts, Policy Challenges, and a Model of the Gulf of Mexico Hypoxic Zone." Review of Environmental Economics and Policy 8:58-79.

Roberts, M.J., and W. Schlenker. 2013. "Identifying Supply and Demand Elasticities of Agricultural Commodities: Implications for the US Ethanol Mandate." American Economic Review 103:2265-2295.

Robertson, D., and J. Symons. 1992. "Some Strange Properties of Panel Data Estimators." Journal of Applied Econometrics 7:175-189.

Royer, T.V., M.B. David, and L.E. Gentry. 2006. "Timing of Riverine Export of Nitrate and Phosphorus from Agricultural Watersheds in Illinois: Implications for Reducing Nutrient Loading to the Mississippi River." Environmental Science \&3 Technology 40:4126-4131.

Sawyer, J.E., and G.W. Randall. 2008. "Nitrogen Rates." In G. Laing, ed. Final Report: Gulf Hypoxia and Local Water Quality Concerns Workshop. St. Joseph, MI: ASABE, pp. $59-71$.

Schilling, K.E., and R.D. Libra. 2000. "The Relationship of Nitrate Concentrations in Streams to Row Crop Land Use in Iowa." Journal of Environmental Quality 29:18461851.

Searchinger, T., R. Heimlich, R.A. Houghton, F. Dong, A. Elobeid, J. Fabiosa, S. Tokgoz, D. Hayes, and T.H. Yu. 2008. "Use of U.S. Croplands for Biofuels Increases Greenhouse Gases Through Emissions from Land-Use Change." Science 319:1238-1240. 
Secchi, S., P.W. Gassman, M. Jha, L. Kurkalova, and C.L. Kling. 2011. "Potential Water Quality Changes due to Corn Expansion in the Upper Mississippi River Basin." Ecological Applications 21:1068-1084.

Sogbedji, J.M., and G.F. McIsaac. 2006. "Evaluation of the ADAPT Model for Simulating Nitrogen Dynamics in a Tile-Drained Agricultural Watershed in Central Illinois." Journal of Environmental Quality 35:1914-1923.

Srinivasan, R., X. Zhang, and J. Arnold. 2010. "SWAT Ungauged: Hydrological Budget and Crop Yield Predictions in the Upper Mississippi River Basin." Transactions of the ASABE $53: 1533-1546$.

The Economist. 2012. "Blooming Horrible." June 23.

Towe, C., and C.I. Tra. 2013. "Vegetable Spirits and Energy Policy." American Journal of Agricultural Economics 95:1-16.

Tuppad, P., K. Douglas-Mankin, T. Lee, R. Srinivasan, and J. Arnold. 2011. "Soil and Water Assessment Tool (SWAT) Hydrologic/Water Quality Model: Extended Capability and Wider Adoption." Transactions of the ASABE 54:1677-1684.

Wu, J., R.M. Adams, C.L. Kling, and K. Tanaka. 2004. "From Microlevel Decisions to Landscape Changes: An Assessment of Agricultural Conservation Policies." American Journal of Agricultural Economics 86:26-41. 
Panel A. Observed Transitions 2009-2010
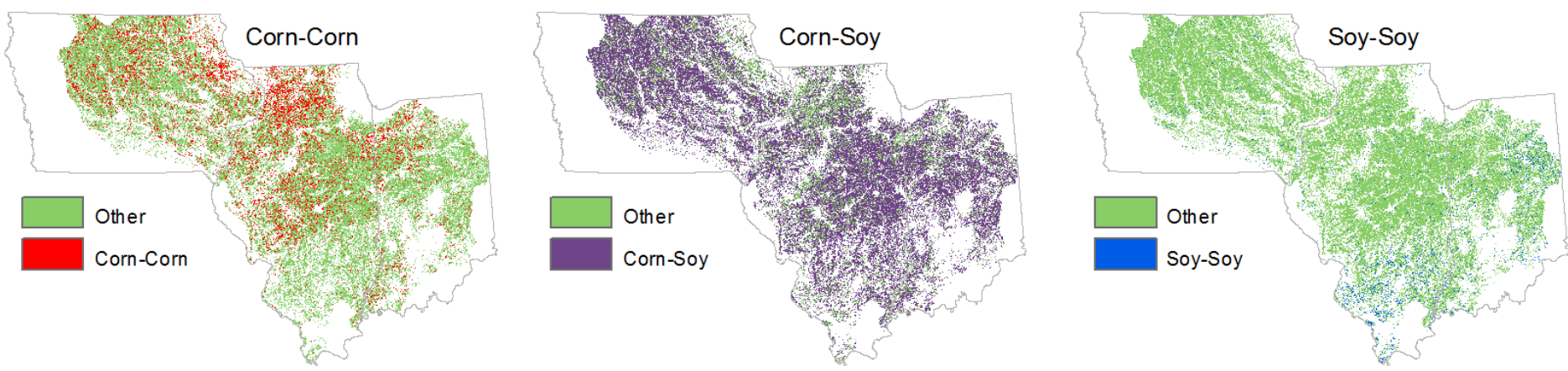

Panel B. Long-Run Probabilities
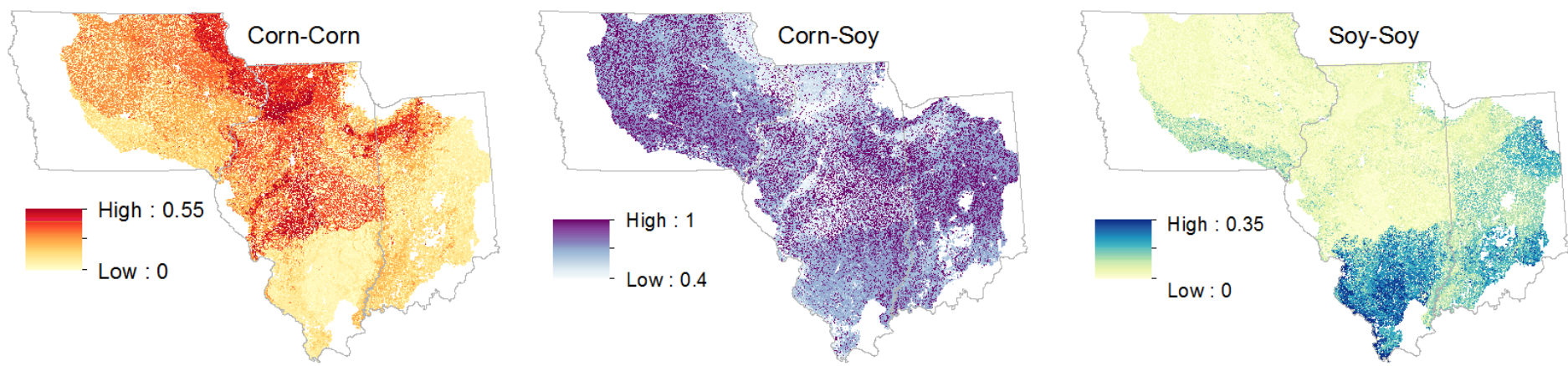

Panel C. Long-Run Change in Probability for a $\$ 1$ Increase in the Price of Corn
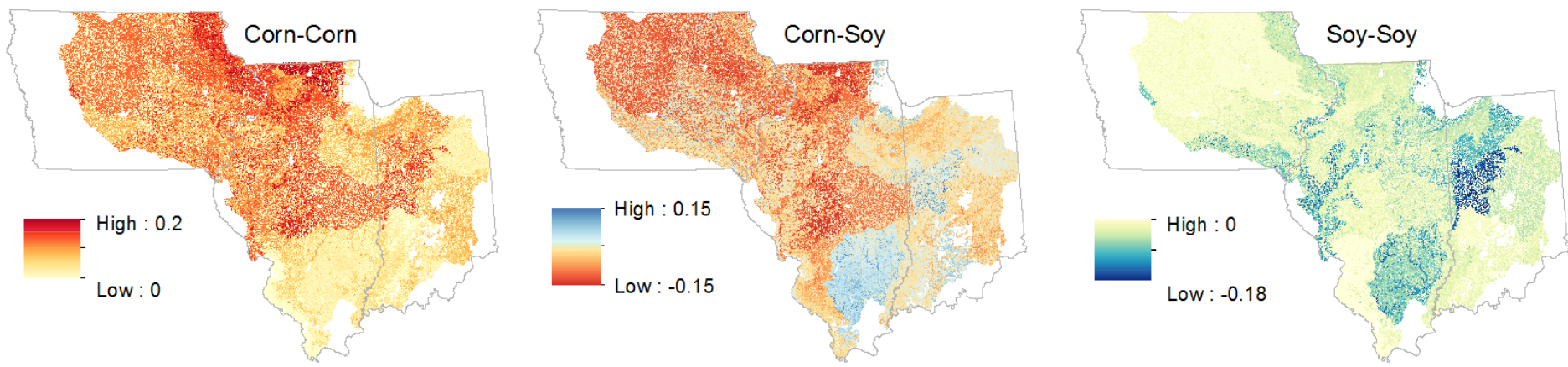

Figure 1: Maps of observed crop transitions and crop rotation results from econometric model 


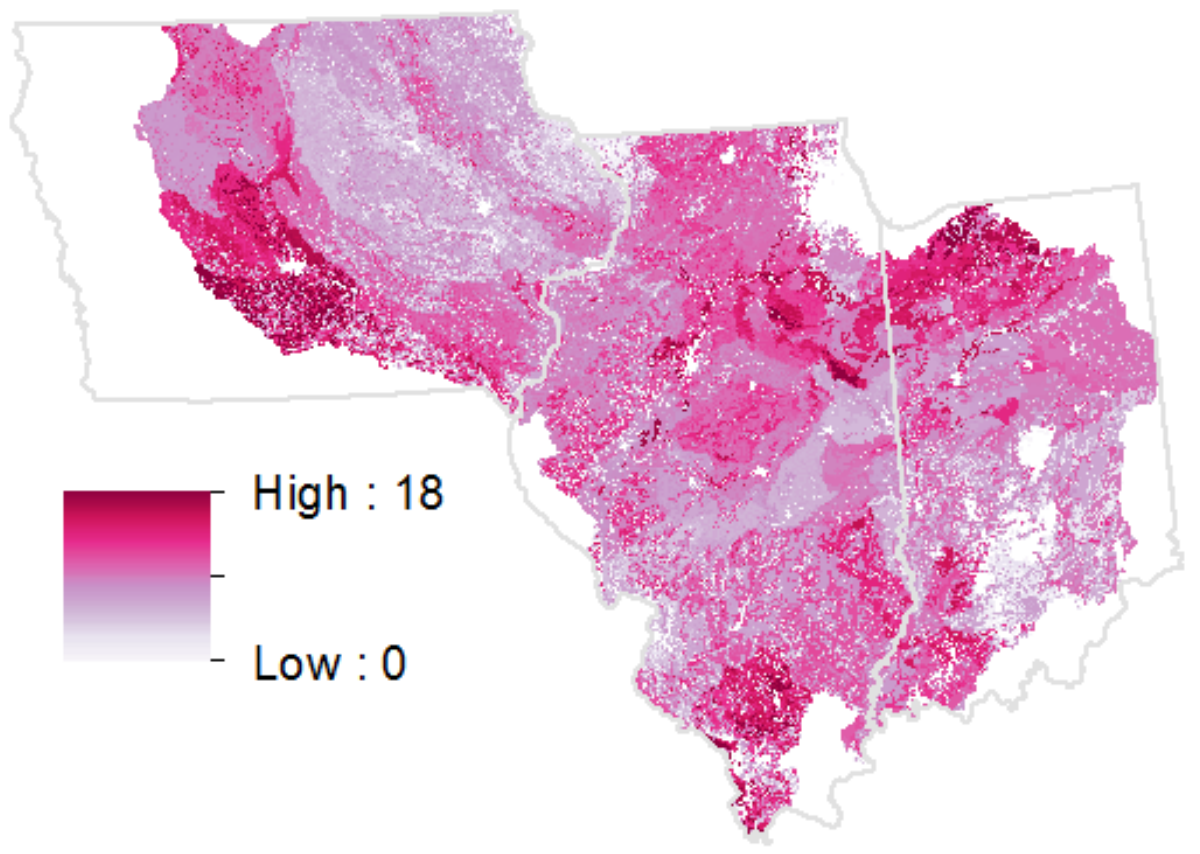

Figure 2: Difference in nitrogen loss from planting corn after corn rather than a corn-soybean rotation 
Long-Run Change in $\mathrm{N}$ Losses for a $\$ 1$ Increase in Price of Corn

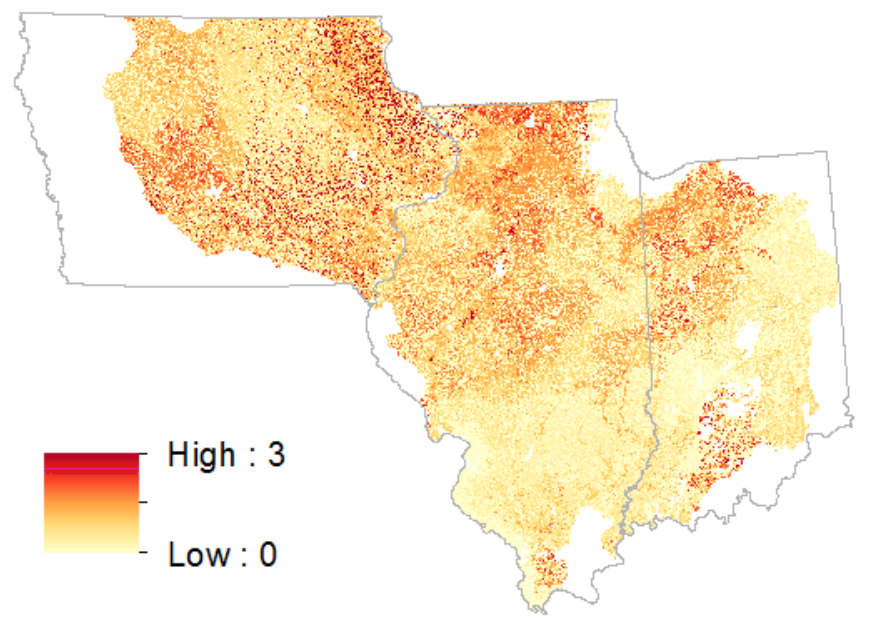

Long-Run Change in $\mathrm{N}$ Losses for a $\$ 1$ Increase in Price of Soybeans

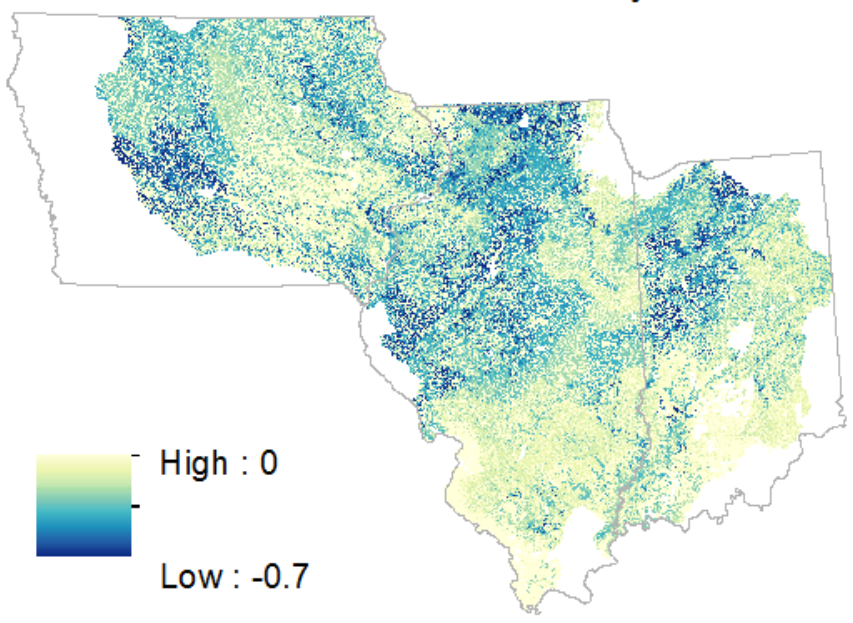

Figure 3: Change in nitrogen losses due to changes in prices 
Table 1: Descriptive statistics of the samples for econometric estimates

\begin{tabular}{lcc}
\hline \hline & Mean & Std. Dev. \\
\hline Panel A. Rotational Margin Sample & $(\mathrm{N}=8,369,302)$ \\
Corn & 0.54 & 0.50 \\
Soybeans & 0.46 & 0.50 \\
Corn after Corn & 0.16 & 0.36 \\
Corn after Soybeans & 0.39 & 0.49 \\
Soybeans after Corn & 0.39 & 0.49 \\
Soybeans after Soybeans & 0.07 & 0.26 \\
Never Monoculture & 0.32 & 0.47 \\
Monoculture at Least Once & 0.68 & 0.47 \\
& & \\
Panel B. Other-Crop Margin Sample & $\mathrm{N}=8,753,448)$ \\
Corn or Soybeans & 0.98 & 0.13 \\
Other Crops & 0.02 & 0.13 \\
Always Corn or Soybeans & 0.89 & 0.32 \\
Other Crop at Least Once & 0.11 & 0.32 \\
& & \\
Expected Price of Corn (\$/bu) & 3.18 & 0.86 \\
Expected Price of Soybeans (\$/bu) & 7.54 & 1.85 \\
Index of Corn and Soybean Prices & 1.21 & 0.31 \\
Index of Alfalfa and Wheat Prices & 1.27 & 0.29 \\
Share Clay & 0.27 & 0.07 \\
Share Silt & 0.51 & 0.15 \\
Slope & 2.99 & 3.40 \\
Large Spring Rainfall & 0.25 & 0.43 \\
Share Irrigated & 0.01 & 0.04 \\
\hline
\end{tabular}

Notes: Panel A gives descriptive statistics for the rotational margin sample - observations (field-year pairs) that were classified as corn or soybeans in two consecutive years. Panel B gives descriptive statistics for the other-crop margin sample - observations that were classified as a crop but where the field was classified as corn or soybeans at least once during the sample period and for which there is a crop observed in two consecutive years. The mean and standard deviation of independent variables are very similar in the rotational sample. 
Table 2: Aggregate corn and soybean acreage elasticities for all fields in Iowa, Illinois, and Indiana

\begin{tabular}{|c|c|c|c|}
\hline & $\begin{array}{c}\text { Rotational } \\
(1) \\
\end{array}$ & $\begin{array}{c}\text { Other Crop } \\
(2)\end{array}$ & $\begin{array}{c}\text { Total } \\
(3)\end{array}$ \\
\hline \multicolumn{4}{|c|}{ Panel A. Corn Acreage Elasticities } \\
\hline \multicolumn{4}{|c|}{ Expected Price of Corn } \\
\hline Short-run & $\begin{array}{l}0.40^{* *} \\
(0.095)\end{array}$ & $\begin{array}{c}0.003 \\
(0.003)\end{array}$ & $\begin{array}{l}0.40^{* *} \\
(0.095)\end{array}$ \\
\hline Long-run & $\begin{array}{l}0.29^{* *} \\
(0.071)\end{array}$ & $\begin{array}{c}0.005 \\
(0.010)\end{array}$ & $\begin{array}{l}0.29^{* *} \\
(0.071)\end{array}$ \\
\hline \multicolumn{4}{|c|}{ Expected Price of Soybeans } \\
\hline Short-run & $\begin{array}{l}-0.31^{* *} \\
(0.104)\end{array}$ & $\begin{array}{c}0.002 \\
(0.002)\end{array}$ & $\begin{array}{l}-0.31^{* *} \\
(0.104)\end{array}$ \\
\hline Long-run & $\begin{array}{l}-0.22^{* *} \\
(0.084)\end{array}$ & $\begin{array}{c}0.003 \\
(0.007)\end{array}$ & $\begin{array}{l}-0.22^{* *} \\
(0.084)\end{array}$ \\
\hline \multicolumn{4}{|c|}{$\begin{array}{l}\text { Panel B. Soybean Acreage Elasticities } \\
\text { Expected Price of Soybeans }\end{array}$} \\
\hline Short-run & $\begin{array}{l}0.36^{* *} \\
(0.122)\end{array}$ & $\begin{array}{c}0.001 \\
(0.002)\end{array}$ & $\begin{array}{l}0.36^{* *} \\
(0.123)\end{array}$ \\
\hline Long-run & $\begin{array}{l}0.26^{* *} \\
(0.099)\end{array}$ & $\begin{array}{c}0.002 \\
(0.008)\end{array}$ & $\begin{array}{l}0.26^{* *} \\
(0.099)\end{array}$ \\
\hline \multicolumn{4}{|c|}{ Expected Price of Corn } \\
\hline Short-run & $\begin{array}{l}-0.47^{* *} \\
(0.112)\end{array}$ & $\begin{array}{c}0.002 \\
(0.003)\end{array}$ & $\begin{array}{l}-0.47^{* *} \\
(0.112)\end{array}$ \\
\hline Long-run & $\begin{array}{l}-0.34^{* *} \\
(0.083)\end{array}$ & $\begin{array}{c}0.004 \\
(0.011)\end{array}$ & $\begin{array}{l}-0.33^{* *} \\
(0.085)\end{array}$ \\
\hline$\frac{\varepsilon_{L R}-\varepsilon_{S R}}{\varepsilon_{L R}}$ & $\begin{array}{l}-0.39^{* *} \\
(0.033)\end{array}$ & $\begin{array}{c}0.41 \\
(0.243)\end{array}$ & $\begin{array}{l}-0.38^{* *} \\
(0.050)\end{array}$ \\
\hline
\end{tabular}

Notes: Aggregate elasticities are calculated as the elasticity of the average marginal effect of price across all fields, weighted by the size of the fields. Results in column (1) are from linear Markov transition probability models as specified in equations (1)-(2). The transition probabilities are estimated separately for soilclimatic regimes. Within each soil-climatic regime, the model is estimated for fields that were planted to monoculture at least once and the price response is assumed to be zero for those fields that were never planted to monoculture. Results in column (2) are from Markov transition models in equations (12)-(13). The transition probabilities are estimated separately for soil-climatic regimes. Within each soil-climatic regime, the model is estimated for those fields that transitioned between corn or soybeans and other crops and the price response is assumed to be zero for fields that were always planted to corn or soybeans. The last row gives the relative difference in the long-run $\left(\varepsilon_{L R}\right)$ and short-run $\left(\varepsilon_{S R}\right)$ elasticities that is analogous to the coefficient on a single lagged dependent variable. Standard errors are clustered by year and estimated with a wild bootstrap.

${ }^{* *}$ Significant at the 5 percent level.

*Significant at the 10 percent level. 
Table 3: Aggregate crop rotation elasticities for all fields in Iowa, Illinois, and Indiana

\begin{tabular}{cccc}
\hline \hline & $\begin{array}{c}\text { Corn after Corn } \\
(1)\end{array}$ & $\begin{array}{c}\text { Corn-Soybeans } \\
(2)\end{array}$ & $\begin{array}{c}\text { Soybeans after Soybeans } \\
(3)\end{array}$ \\
\hline Expected Price of Corn & & -0.10 & $-0.91^{* *}$ \\
Short-run & $0.93^{* *}$ & $(0.059)$ & $(0.292)$ \\
& $(0.276)$ & $-0.15^{*}$ & $-1.34^{* *}$ \\
Long-run & $1.33^{* *}$ & $(0.069)$ & $(0.459)$ \\
Expected Price of Soybeans & $(0.373)$ & & \\
Short-run & $-0.80^{* *}$ & $0.11^{*}$ & $0.54^{*}$ \\
& $(0.289)$ & $(0.053)$ & $(0.250)$ \\
Long-run & $-1.12^{* *}$ & $0.15^{*}$ & 0.86 \\
& $(0.416)$ & $(0.071)$ & $(0.720)$ \\
$\frac{\varepsilon_{L R}-\varepsilon_{S R}}{\varepsilon_{L R}}$ & & & $0.32^{* *}$ \\
& $0.30^{* *}$ & $0.28^{* *}$ & $(0.122)$ \\
\hline
\end{tabular}

Notes: Aggregate elasticities are calculated as the elasticity of the average marginal effect of price across all fields, weighted by the size of the fields. These elasticities represent results from the same regressions as column 1 of table 2 . The short-run and long-run marginal effects of corn after corn are calculated as in equations (10) and (11) and marginal effects for a cornsoybean rotation and soybeans after soybeans are calculated similarly from derivatives of (8) and (9). Standard errors are clustered by year and estimated with a wild bootstrap.

${ }^{* *}$ Significant at the 5 percent level.

*Significant at the 10 percent level. 
Table 4: Average nitrogen losses (lbs/acre) at the edge of field for different land uses

\begin{tabular}{lcc}
\hline \hline & Mean & Std. Dev. \\
\hline Corn after Corn & 34.7 & 11.4 \\
Corn after Soy & 25.4 & 10.3 \\
Soy after Corn & 25.9 & 10.6 \\
Soy after Soy & 24.9 & 10.8 \\
Wheat & 7.7 & 5.7 \\
Oats & 9.6 & 5.4 \\
Alfalfa & 12.6 & 8.0 \\
CRP & 2.2 & 1.9 \\
\hline
\end{tabular}

Notes: This table gives results from the Soil and Water Assessment Tool (SWAT). Results give average and standard deviation - weighted by size of fields - of total nitrogen losses at the edge of field. Total nitrogen is the sum of nitrates and organic nitrogen. 
Table 5: Elasticities of nitrogen losses excluding CRP conversions

\begin{tabular}{cccc}
\hline \hline & \multicolumn{3}{c}{ Response to Price } \\
\cline { 2 - 4 } & $\begin{array}{c}\text { Heterogeneous } \\
(1)\end{array}$ & $\begin{array}{c}\text { Average } \\
(2)\end{array}$ & $\begin{array}{c}\text { Pooled } \\
(3)\end{array}$ \\
\hline Expected Price of Corn & $0.050^{* *}$ & $0.051^{* *}$ & 0.037 \\
Short-run & $(0.014)$ & $(0.014)$ & $(0.023)$ \\
Long-run & $0.076^{* *}$ & $0.076^{* *}$ & 0.048 \\
& $(0.020)$ & $(0.020)$ & $(0.059)$ \\
Expected Price of Soybeans & & \\
Short-run & $-0.036^{* *}$ & $-0.041^{* *}$ & -0.017 \\
Long-run & $(0.014)$ & $(0.015)$ & $(0.023)$ \\
& $-0.053^{* *}$ & $-0.059^{* *}$ & -0.022 \\
& $(0.021)$ & $(0.022)$ & $(0.047)$ \\
$\frac{\varepsilon_{L R}-\varepsilon_{S R}}{\varepsilon_{L R}}$ & & & \\
& $0.34^{* *}$ & $0.33^{* *}$ & 0.23 \\
& $(0.026)$ & $(0.063)$ & $(0.303)$ \\
\hline
\end{tabular}

Notes: Elasticities in this table give the percent change in average nitrogen losses from a 1 percent increase in corn or soybean prices calculated using equation (17). Column (1) reports elasticities using econometric results that are estimated separately for soil-climatic regimes and transition groups as in tables 2 and 3 . Column (2) reports elasticities using the average marginal effects of land use response to prices rather than spatially heterogeneous responses, but the same econometric model as in column (1). Column (3) reports elasticities imposing common coefficients for all fields (i.e., pooling) in the econometric estimation.

${ }^{* *}$ Significant at the 5 percent level.

*Significant at the 10 percent level. 